\title{
Caractéristiques et maîtrise de la fonction de reproduction chez les cervidés
}

Y. LOCATELLII,2, P. MERMILLOD2

${ }^{1}$ Muséum National d'Histoire Naturelle, Département des Parcs et Jardins Botaniques et Zoologiques, Réserve Animalière de la Haute Touche, F-36290 Obterre

2 INRA, Physiologie de la Reproduction et des Comportements, F-37380 Nouzilly

Courriel :ylocatel@tours.inra.fr

L'extraordinaire diversité taxonomique de la famille des cervidés se caractérise par des différences marquées entre les espèces (répartitions géographiques, morphologies ou encore carctéristique de la physiologie de la reproduction). La préservation de cette diversité repose aujourd'hui sur la réalisation de programmes conservatoires qui nécessitent d'approfondir nos connaissances de la physiologie de la reproduction de ces ruminants sauvages.

De par le monde, le nombre d'espèces de mammifères menacées d'extinction est en augmentation. La diminution de populations dans le milieu naturel résulte souvent d'activités humaines entraînant la modification de l'écosystème (Ceballos et Ehrlich 2002). L'industrialisation, l'agriculture intensive, le braconnage, les pollutions ou encore les guerres sont autant de facteurs favorisant l'extinction d'espèces. L'extraordinaire diversité de la famille des cervidés est directement touchée par ce phénomène. Parmi la quarantaine d'espèces que comptent les cervidés, plus d'une trentaine de sous-espèces (sur un total de près de 200) figurent sur la liste rouge des animaux menacés d'extinction de 1' IUCN ou International Union for Conservation of Nature and Natural Resources (tableau 1). Les cerfs sika de Formose (Cervus nippon taiouanus), du Viêt-Nam (Cervus nippon pseudaxis), le cerf de Duvaucel (Cervus duvaucelii) ou encore le daim de Mésopotamie (Dama dama mesopotamica) figurent parmi les plus menacés. Certains cervidés, comme le cerf du Père David (Elaphurus davidianus), ont totalement disparu de leur habitat naturel et leur sauvegarde ne dépend plus que de programmes conservatoires ex situ, menés, pour la plupart, dans des parcs zoologiques. Les faibles effectifs de géniteurs, la consanguinité, la faible prolificité ou l'inadéquation des conditions de vie en captivité sont souvent un obstacle à l'obtention de descendants.
Chez les mammifères domestiques, les nombreuses recherches dans le domaine du contrôle et de la conduite de la reproduction ont permis l'acquisition de connaissances et le développement d'outils biotechnologiques performants, notamment chez les ovins et caprins (Chemineau et al
1999). Chez les cervidés, la cryoconservation de gamètes, la superovulation, l'insémination artificielle (IA), la fécondation in vitro (FIV) et le transfert d'embryons permettraient l'augmentation des effectifs à partir d'un faible nombre de géniteurs. La constitution de banques cryogéniques

Tableau 1. Répartition des sous espèces menacées d'extinction au sein de la famille des cervidés (sources IUCN 2000).

\begin{tabular}{|c|c|c|c|}
\hline Genre & $\begin{array}{c}\text { Nombre } \\
\text { d'espèces }\end{array}$ & $\begin{array}{c}\text { Nombre } \\
\text { de sous-espèces } \\
\text { (dont éteintes) }\end{array}$ & $\begin{array}{c}\text { Nombre de sous- } \\
\text { espèces } \\
\text { menacées } \\
\text { d'extinction }\end{array}$ \\
\hline Alces & 1 & 6 & 1 \\
\hline Axis & 4 & 4 & 3 \\
\hline Blastocerus & 1 & - & 1 \\
\hline Capreolus & 1 & 3 & - \\
\hline Cervus & 9 & $65(2)$ & 20 \\
\hline Dama & 1 & 2 & 1 \\
\hline Elaphodus & 1 & 3 & - \\
\hline Elaphurus & 1 & - & 1 \\
\hline Hippocamelus & 2 & - & 1 \\
\hline Hydropotes & 1 & 2 & 2 \\
\hline Mazama & 4 & 26 & 1 \\
\hline Moschus & 3 & 4 & - \\
\hline Muntiacus & 5 & 17 & 1 \\
\hline Odocoileus & 2 & 49 & 3 \\
\hline Ozotoceros & 1 & 3 & 3 \\
\hline Pudu & 2 & 2 & 2 \\
\hline \multirow[t]{2}{*}{ Rangifer } & 1 & $9(2)$ & 1 \\
\hline & 40 & $195(4)$ & 41 \\
\hline
\end{tabular}


de gamètes et d'embryons, en plus de son aspect conservatoire, faciliterait les échanges de matériels génétiques entre les différents sites de conservation ex situ et diminuerait ainsi le phénomène de consanguinité. Pour développer des programmes conservatoires basés sur ces techniques chez les cervidés, il conviendrait d'améliorer les connaissances fondamentales de la physiologie de la reproduction afin d'adapter les techniques de procréation assistée déjà utilisées avec succès pour les mammifères domestiques. Depuis une trentaine d'années, suite à l'essor de l'élevage de daims et de cerfs élaphe (en Nouvelle-Zélande notamment), de nombreux travaux de recherches ont porté sur la caractérisation de la physiologie de la reproduction des cervidés et plus récemment sur la mise au point et l'utilisation des méthodes de procréation assistée. Ils concernent le plus souvent le cerf élaphe ou cerf rouge (Cervus elaphus), le cerf de Virginie (Odocoileus virginianus), le Wapiti (Cervus canadensis) ou encore le daim (Dama dama). Trois difficultés majeures se présentent dans l'application des outils biotechnologiques chez les cervidés. La première est liée au fait que la plupart des cervidés présentent un cycle saisonnier très marqué de leur fonction de reproduction, avec une période d'inactivité sexuelle profonde. La conduite de protocoles d'assistance à la procréation en dehors de la saison sexuelle a de ce fait peu de chances de succès. De plus, la très grande diversité de la famille des cervidés ne se limite pas à une diversité taxonomique ou de répartition géographique mais concerne également les caractéristiques de la physiologie de la reproduction. Enfin le caractère sauvage de ces animaux rend leurs manipulations extrêmement difficiles voire dangereuses pour les expérimentateurs comme pour les animaux eux-mêmes. Le stress associé ne doit pas être négligé car il peut être la cause d'échecs (Asher et al 1996b, Carragher et al 1997).

Dans cette revue bibliographique, nous traiterons des caractéristiques générales de la fonction de reproduction chez les cervidés et notamment de l'aspect saisonnier de cette reproduction. Nous traiterons également de l'avancée des connaissances concernant les méthodes de procréation assistée appliquées à ces espèces sauvages.

\section{1 / Caractéristiques de la fonction de reproduction des cervidés}

\section{1 / Aspects saisonniers : géné- ralités}

Comme de nombreux mammifères originaires des zones tempérées, la plupart des cervidés présentent un caractère très saisonné de leur fonction de reproduction qui se traduit par une alternance entre des périodes d'activité et d'inactivité sexuelles, dictée par les rythmes photopériodiques (variation de la durée du jour). Sous nos latitudes, la période du rut ainsi que le maximum de fertilité sont généralement observés en automne (septembre-octobre) pendant les jours courts et sur une très courte période (Lincoln 1971, Lincoln 1998). Dans le cas du cerf élaphe, la période d'accouplement ne dépasse pas trois semaines. Ainsi, compte tenu de la durée de gestation, les naissances ont lieu au printemps, période favorable à la croissance des jeunes. Au contraire, la mise en sommeil de la fonction de reproduction empêche la conception de jeunes dont les naissances interviendraient dans une période défavorable.

Chez les mammifères, le signal photopériodique doit cheminer depuis l'œil vers les gonades et son intégration fait intervenir des mécanismes complexes, impliquant les systèmes nerveux et endocrinien (Malpaux et al 1996). Le signal lumineux est perçu par la rétine puis transmis par voie nerveuse vers les noyaux supra-chiasmatiques, les noyaux hypothalamiques paraventriculaires et les ganglions cervicaux supérieurs. Le signal atteint ensuite la glande pinéale qui secrète la mélatonine. Chez les ovins et caprins, la mélatonine est secrétée pendant la nuit alors que les niveaux diurnes sont faibles (Arendt 1986). Ainsi, la durée quotidienne (durée de présence), l'amplitude (différence entre niveaux diurnes et nocturnes) et la phase (moment de présence) de sécrétion de mélatonine sont modifiées au cours de l'année suite aux variations de la durée du jour et sont susceptibles de réguler la fonction de reproduction en agissant au niveau central sur l'activité de l'axe hypothalamo-hypohysaire. Chez les ovins, comme chez le cerf élaphe, des sites spécifiques de liaison de la mélatonine ont été identifiés dans la pars tuberalis, au niveau des colliculus supérieurs, des plexus choroïdes et dans l'hippocampe (Lincoln 1998).
Chez le cerf élaphe, la pars distalis est également un site de liaison spécifique (Williams et al 1996). Toutefois, les structures précises et les mécanismes impliqués dans le contrôle de la saisonnalité restent à déterminer. Il semble que la mélatonine agisse au niveau de l'hypothalamus medio basal sur les sécrétions pulsatiles de GnRH (Gonadotropin Releasing Hormone). Ainsi les sécrétions en hormones sexuelles ou hormones gonadotropes LH et FSH (Luteinizing and Follicle Stimulating Hormone) sont elles modifiées par la mélatonine au cours de l'année via le GnRH. Les variations de sécrétions d'hormones gonadotropes ont pour conséquence de moduler l'activité des gonades (ovaires et testicules).

\section{2 / La fonction de reproduc- tion chez le mâle}

Chez le bélier ou le bouc sous nos latitudes, des variations saisonnières du poids et volume testiculaire ainsi que de production spermatique quotidienne sont observées. Ainsi, la production spermatique quotidienne chez le bélier Ile-de-France est quatre fois plus élevée en automne qu'au printemps (Dacheux et al 1981). Chez les cervidés originaires des zones tempérées (cerf élaphe, daim, chevreuil notamment) ces variations prennent des proportions plus importantes que celles décrites chez les animaux domestiques. Nous traiterons ici du cas général et nous verrons que la variété des répartitions géographiques et des stratégies évolutives ont généré un certain nombre d'exceptions, avec des espèces au profil reproductif particulier.

\section{a) Activité sexuelle}

Chez les cervidés originaires des zones tempérées, il est possible d'observer des cycles annuels de pousse des bois ainsi que des variations de volume testiculaire et de testostéronémie. L'association de ces cycles chez le daim d'Europe et le chevreuil adulte sont représentés dans la figure 1. Sous nos latitudes, la période du rut se situe en juillet-août pour le chevreuil, septembre-octobre pour les cerfs élaphe et sika et en octobre-novembre pour le daim (sika : Hamasaki et al 2001, Kameyama et al 2002, daim : Gosch et Fischer 1989). Le volume testiculaire, les concentrations de testostérone plasmatique et de spermatozoïdes dans l'éjaculat ainsi que la proportion de spermatozoïdes normaux augmentent fortement dans la période qui précède le rut et atteignent un maximum durant celuici (figure 1). La fertilité des mâles est 
Figure 1. Comparaison de l'influence de la durée du jour sur la pousse des bois, le volume testiculaire, la testostéronémie, la quantité et la morphologie des spermatozoïdes entre le daim d'Europe et le chevreuil (adapté de Gosch et Fischer 1989 et de Goeritz et al 2003).
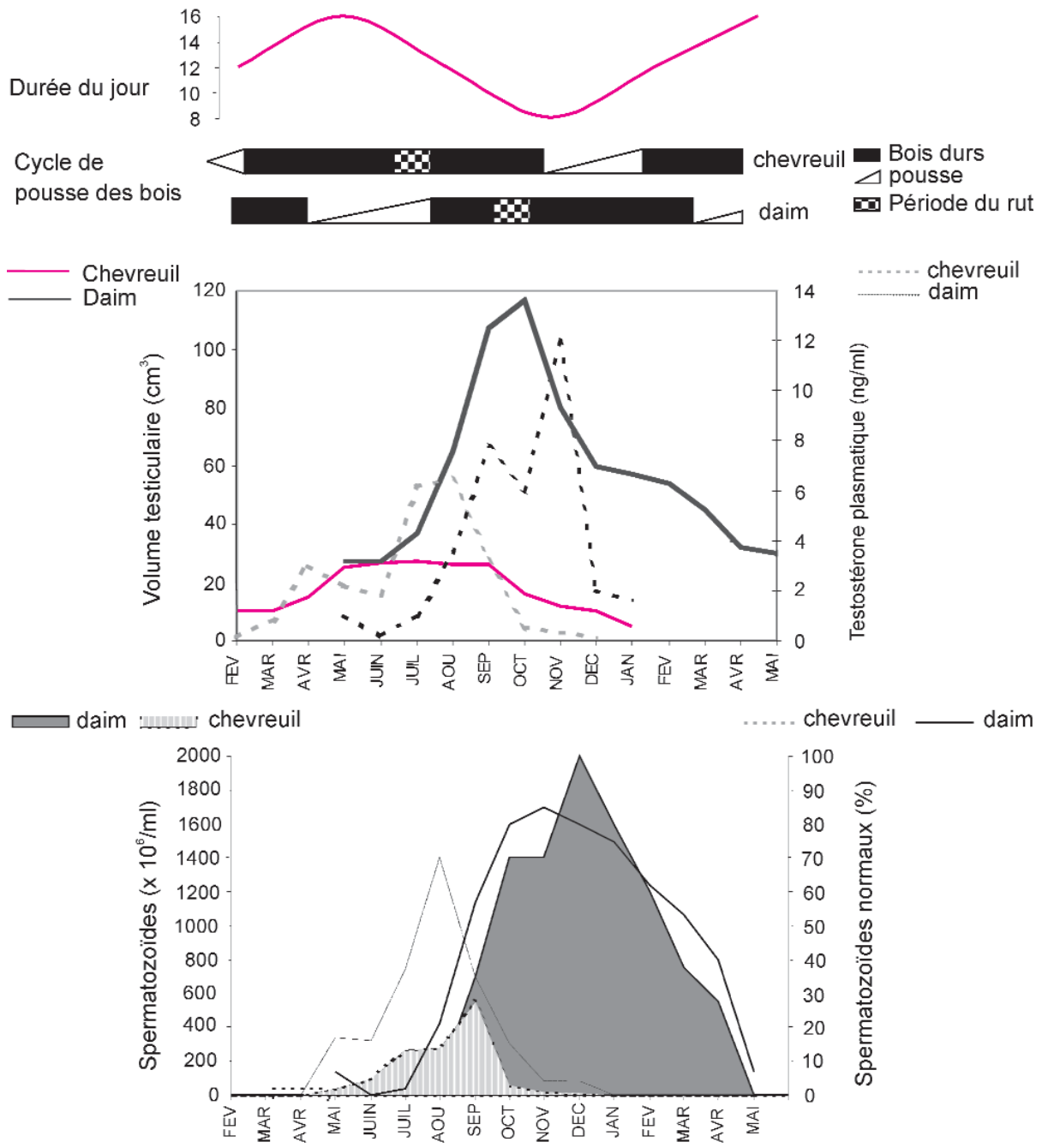

alors remarquable puisque dans les élevages, il n'est pas rare de voir utiliser un mâle pour saillir plus d'une cinquantaine de biches sur une période ne dépassant pas trois semaines avec un taux de mise bas au printemps de l'ordre de $90 \%$. Dans la période qui suit le rut, les différents paramètres précités diminuent plus ou moins progressivement jusqu'au printemps. Chez le chevreuil, il est à noter que les types d'anomalies observés sur les spermatozoïdes diffèrent en proportions au cours de la saison sexuelle. Les anomalies prédominantes concernent la tête en début de saison sexuelle et le flagelle en fin de saison (Goeritz et al 2003). La taille testiculaire fait l'objet d'une régression spectaculaire puisqu'elle est près de 4 fois moins importante au printemps au moment de la chute des bois que lors du rut (élaphe : Hochereau-de Reviers et Lincoln 1978). Chez l'élaphe, le daim ou le chevreuil, la production spermatique chute jusqu'à une aspermie complète pendant la phase de repousse

\section{b) Hormones gonadotropes}

Chez le daim, des différences notables de concentration et de pulsatilité de LH peuvent être observées au cours de l'année et plus particulièrement durant la transition de la phase d'inactivité vers la phase d'activité sexuelle (Asher et al 1989a, Asher et Peterson 1991). Les niveaux de LH sont très faibles du mois de décembre au mois de juin et élevés de juillet à octobre. La pulsatilité de LH augmente de 0-2 pulses / $24 \mathrm{~h}$ à environ 5-7 pulses / $24 \mathrm{~h}$ entre les mois de juillet et août. En septembre et octobre, bien que la pulsatilité de $\mathrm{LH}$ diminue (0-1 pulse par $24 \mathrm{~h})$ les concentrations restent élevées et les niveaux de testostérone sont alors fortement augmentés. Chez le mâle castré, la sécrétion pulsatile de LH est également plus élevée durant la transition vers la phase d'activité sexuelle. Les concentrations et la pulsatilité de $\mathrm{LH}$ observées chez les mâles castrés sont toujours plus élevées que chez les mâles entiers. Les modifications de sécrétions d'hormones gonadotropes semblent influencées par la saison sexuelle de façon dépendante des stéroïdes testiculaires.

\section{c) Contrôle de la saisonnalité}

L'influence de la photopériode sur le cycle des bois et sur les variations hormonales associées a été clairement démontrée chez le daim, le sika ou l'élaphe puisqu'il est possible d'induire des cycles inversés ou accélérés de pousse de bois et de variations testiculaires au cours d'une même année en soumettant des mâles de ces espèces à un régime photopériodique inversé ou accéléré (Goss 1969a, Suttie et al 1989, Rolf et Fischer 1996). Cependant, dans certaines conditions d'accélération du régime photopériodique, il est possible d'observer un décalage du cycle des bois, permettant chute, croissance et minéralisation pendant la phase de diminution de la durée du jour (Rolf et Fischer 1996). Chez le cerf de virginie (Odocoileus virginianus), la pinéalectomie provoque une désynchronisation du cycle d'activité sexuelle. En comparaison d'animaux témoins, un retard de trois mois environ peut être observé dans les variations de diamètre scrotal, la date de début de croissance, de minéralisation et de chute des bois. Dans ce cas, les variations de prolactine dans le sang périphérique suivent un profil identique au regard du cycle des bois mais pas au regard de la photopériode (Snyder et al 1983). De même, l'exposition de cerfs sika à des jours longs ou courts dont la durée est constante per- 
met la croissance et la chute de bois mais à des intervalles irréguliers (Goss 1969b). Ainsi, chez les cervidés comme chez les ovins, les variations photopériodiques semblent permettre d'induire et de synchroniser un rythme endogène de variation d'activité sexuelle via les sécrétions de mélatonine par la glande pinéale. Chez l'élaphe, l'administration d'implants de mélatonine à des mâles, ayant subi ou non une ablation des ganglions cervicaux supérieurs au mois de mai, permet la minéralisation précoce des bois, signe de modifications des sécrétions d'hormones gonadotropes. Un rappel d'immunisation active contre le GnRH, immédiatement après cette minéralisation précoce provoque la chute des bois environ 30 jours plus tard. Chez ces cervidés, il semble que le principal mécanisme d'entrée en saison sexuelle soit dépendant des variations photopériodiques et de sécrétion de mélatonine qui, à l'instar des caprins ou ovins, modifieraient les sécrétions d'hormones gonadotropes par action sur le système à GnRH (Lincoln et al 1984).

Si le mécanisme d'entrée en saison sexuelle a été relativement bien étudié chez les cervidés, peu de données concernent la transition vers la période d'inactivité sexuelle. Il est probable que les variations photopériodiques (augmentation de la durée du jour) soient responsables de ce phénomène. Cependant, il est possible que d'autres facteurs hormonaux tels que les hormones thyroïdiennes puissent jouer un rôle important. En effet, chez la brebis ou le bélier, la thyroïdectomie abolit les variations saisonnières d'activité sexuelle ou de sécrétions de LH (Moenter et al 1991). Chez le mâle élaphe, en fin de saison sexuelle, une élévation des concentrations d'hormones thyroïdiennes peut être observée (Loudon et al 1989, Shi et Barrell 1994). Chez l'élaphe, la thyroïdectomie retarde la période de repos sexuel ou empêche celle-ci d'avoir lieu. L'administration quotidienne d'hormones $\mathrm{T} 4$, permet de rétablir la régression testiculaire et la chute des bois. Il est toutefois à noter que l'administration précoce de T4 ne permet pas d'avancer la fin de la saison sexuelle (Shi et Barell 1994).

d) Les bois, un caractère sexuel secondaire qui reflète les variations d'activité sexuelle

Chez les cervidés, les bois sont un caractère sexuel secondaire caractéristique du mâle, exception faite pour le renne (Rangifer tarandus) dont la femelle porte également des bois. Pour ces femelles, le fait de porter des bois est un avantage puisqu'elles les utilisent comme moyen de défense contre les prédateurs (période coïncidant avec la gestation) mais également comme outils pour atteindre leur nourriture dans le sol gelé. Les bois sont des prolongements des os frontaux, ramifiés et caducs. Chez les mâles et au moment $\mathrm{du}$ rut, les bois sont utilisés dans les combats engagés pour l'établissement d'une hiérarchie. Le bois de cerf est une structure qui doit être solide (jusqu'à $8 \mathrm{~kg}$ d'os compact chez l'élaphe) pour répondre à la violence des combats et permettre ainsi aux mâles dominants d'accéder à la reproduction. Il est probable de ce point de vue qu'au cours de l'évolution, la solidité des bois ait été un critère sélectif déterminant. Le cycle annuel des bois comprend des phases de pousse (bois en velours), de minéralisation (bois durs ou secs) et de chute. Ces modifications influencent les habitudes territoriales du mâle qui préférera les zones de plaines lors de la fragile phase de pousse des bois et les sous-bois, après la minéralisation.

Chez le cerf élaphe, lors de la première année et au moment de la puberté, se développent deux excroissances depuis l'os frontal de la boite crânienne : les pivots. L'âge auquel débute la croissance des pivots varie entre le $5^{\mathrm{e}}$ et le $^{\mathrm{e}}$ mois de vie. Il est influencé par l'état nutritionnel de l'animal (retardé en cas de restriction alimentaire), mais semble également dépendre de l'entraînement photopériodique (Suttie et al 1984, Fennessy et Suttie 1985, Suttie et al 1989, Suttie et al 1991, Webster et al 1999). Le développement des pivots est associé à l'augmentation du volume testiculaire et des niveaux de testostérone plasmatique (Suttie et al 1984, Suttie et al 1991). En effet, la castration du mâle pré pubère empêche le développement des pivots qui peut alors être rétabli grâce à l'administration de testostérone exogène (Wislocki et al 1947). De même, il est possible d'induire la formation et la pousse de bois chez la femelle par un apport de testostérone exogène ( $\mathrm{Li}$ et al 2003). Si la testostérone est nécessaire à la formation des pivots, l'administration d'une forte dose exogène inhibe la croissance des bois (Goss 1968). Durant cette phase de formation des pivots, l'amplitude des pulses de LH diminue quelque peu mais leur fréquence augmente $(3,37$ vs 7,67 pulses / 24 h) entraînant une hausse de la fréquence des pulses de testostérone et donc une élévation importante des niveaux plasmatiques (Lincoln 1971, Suttie et al 1991).

Les premiers bois (dagues, non ramifiés et dépourvus de meules) débutent leur pousse une fois les pivots formés (9e mois). Ils sont recouverts du velours, qui assure vascularisation et protection. Après 12 semaines de pousse, ils atteignent une taille moyenne de $40 \mathrm{~cm}$ (Fennessy et Suttie 1985). Durant cette phase de croissance, on observe une diminution des niveaux plasmatiques moyens de testostérone entraînée par la chute en fréquence et amplitude des pulses de LH (7,67 vs 4,73 pulses / 24 h) (Suttie et al 1991). La croissance du velours terminée, la fréquence des pulses de LH double et la testostéronémie augmente alors fortement, provoquant le dessèchement du velours et sa minéralisation. $\mathrm{Au}$ $15^{\mathrm{e}}$ mois, les bois sont alors dits secs ou durs et sont, en définitive, un tissu osseux mort solidement rattaché au pivot. Les bois durs sont donc le reflet de l'activité testiculaire, traduisant l'augmentation de la testostéronémie du fait de l'androgéno-dépendance de leur minéralisation (Fennessy et Suttie 1985, Suttie et al 1984, Li et al 2003). Signes de l'importance de la testostérone dans ce phénomène, la minéralisation peut être empêchée en procédant à la castration du mâle qui conserve alors des bois de velours (Wislocki et al 1947, Lincoln et Kay 1979). Si elle est réalisée après la minéralisation, la castration provoque la chute des bois tandis que l'administration de testostérone permet leur maintien (Wislocki et al 1947). Dans ces deux cas, il est possible de rétablir respectivement la minéralisation et le maintien des bois secs par l'administration de testostérone exogène (Wislocki et al 1947, Li et al 2003). Toutefois, il semble que d'autres facteurs soient impliqués dans la régulation de la croissance et de la minéralisation des bois. Chez la femelle du renne, la testostérone d'origine surrénalienne ne semble pas être impliquée dans la régulation de la minéralisation des bois (Bubenik et al 1997). D'autres stéroïdes sexuels ou facteurs de croissances semblent pouvoir intervenir dans ce phénomène tels que l'oestradiol, l'androstenedione ou l'IGF1 (Insulin like Growth factor) (Goss 1968, Bubenik et al 1987, Lincoln et Tyler 1999).

La chute des bois intervient normalement au printemps, probablement sous l'effet de la photopériode (augmentation de la durée du jour) et de facteurs 
nutritionnels entraînant une diminution progressive de l'amplitude et de la fréquence des pulses de LH et de testostérone. La résultante est une chute dramatique des niveaux de testostérone. Durant près de 2 semaines après la chute des bois, il n'est pas possible d'observer de pulses de LH ou de testostérone (Suttie et al 1992). Un nouveau cycle débute alors avec la croissance de nouveaux bois de velours. Les niveaux de testostérone sont faibles et n'augmentent ensuite que très progressivement jusqu'à la minéralisation.

e) Cas particulier : espèces subtropicales

Les cervidés originaires des zones subtropicales $\left(20^{\circ} \mathrm{S}\right.$ à $\left.20^{\circ} \mathrm{N}\right)$ sont peu saisonnés voir non saisonnés dans leur habitat naturel et il est classiquement admis que ces espèces le restent une fois placées dans des zones tempérées. Mais en fait, plusieurs cas de figures se présentent, traduisant des adaptations différentes des espèces à leur environnement et témoignant de l'extraordinaire diversité de la famille des cervidés. Quelques exemples illustrent bien le phénomène :

- Le cerf axis (Axis axis), qui n'est pas saisonné dans son milieu d'origine (Inde, Sri Lanka...), ne le devient pas lorsqu'il est transporté sous des latitudes moyennes à élevées. En effet, quelque soit la latitude, on observe une répartition des mises bas des femelles assez homogène sur l'année (Loudon et Curlewis 1988). Individuellement, le mâle présente des changements de volume testiculaire et de testostéronémie qui sont bien associés avec le cycle des bois bien que ces variations soient moins marquées que pour l'élaphe ou le daim. Mais, contrairement aux espèces originaires des zones tempérées, le synchronisme du cycle des bois entre les individus semble moins prononcé, y compris sous des latitudes élevées $\left(51^{\circ} \mathrm{N}\right)$. De plus, il est possible de collecter des spermatozoïdes motiles quelque soit le stade du cycle des bois y compris durant la période de repousse (Loudon et Curlewis 1988). Les mêmes auteurs ont suggéré qu'une capacité de stockage de l'épididyme pouvait expliquer le phénomène. Les récents travaux de Willard et Randel, bien que menés sous des latitudes moins élevées $\left(28-32^{\circ} \mathrm{N}\right)$ suggèrent en fait une spermatogenèse continue (Willard et Randel 2002). Il est à noter que dans l'étude de Loudon et Curlewis, l'administration de mélatonine sous forme d'implants sous cutanés à des mâles dont les bois étaient en début de croissance (au mois de mai) n'a eu aucun effet sur la croissance testiculaire ou sur le cycle des bois en comparaison des témoins. Ceci suggère que chez le cerf axis, l'entraînement de l'activité de reproduction par la photopériode et la mélatonine soit inexistant.

- A l'instar du cerf axis, le cerf muntjac (genre Muntiacus) se reproduit toute l'année. Les différentes sousespèces sont principalement distribuées au sud de la Chine, en Malaisie, au Bangladesh ou dans les îles indonésiennes (Sumatra, Bornéo...). Une fois placés sous des latitudes élevées $\left(52^{\circ} \mathrm{N}\right)$, les mâles présentent un synchronisme élevé dans le cycle de pousse des bois qui est assez similaire à ce qui est observé chez l'élaphe. La castration provoque également la chute des bois et empêche la minéralisation des bois en velours mais, chez le muntjac, les variations saisonnières du poids testiculaire ou de la testostéronémie sont nettement moins marquées que chez des espèces originaires des zones tempérées. Comme pour le cerf axis, la spermatogenèse semble rester continue (Chapman et Harris 1991).

- Le cerf d'Eld (espèce originaire d'Indochine et de Chine du Sud) montre dans son milieu d'origine un saisonnement très marqué avec une répartition des mises bas en octobre-novembre. Placé sous des latitudes élevées il conserve ces périodes de reproduction : le rut se déroule lorsque la durée du jour augmente, à savoir en fin d'hiver et au début du printemps avec des mises bas de septembre à novembre. Entre individus, le synchronisme du cycle des bois est élevé et bien associé à la taille testiculaire et à la testostéronémie (Monfort et al 1993b). Quelque soit la saison, il est possible de trouver des spermatozoïdes motiles dans les éjaculats puisque le cerf d'Eld ne semble pas présenter d'aspermatogenèse saisonnée. Par contre, on observe de fortes variations dans la qualité du sperme produit avec une forte proportion de spermatozoïdes anormaux en automne (Montfort et al 1993b).

\section{3 / La fonction de reproduc- tion chez la femelle}

\section{a) Activité sexuelle}

Comme nous avons pu le voir chez le mâle, les femelles originaires des zones tempérées présentent également un cycle saisonnier marqué de leur fonction de reproduction. Chez la biche élaphe adulte, la période d'inactivité sexuelle est caractérisée par un état d'anoestrus associé à une absence d'ovula- tion. L'entrée en saison sexuelle se traduit par une première ovulation silencieuse en septembre-octobre (début avril dans l'hémisphère Sud), suivie d'un premier oestrus 8,7 jours plus tard, synonyme d'une régression prématurée du premier corps jaune ou cycle court (Asher et al 2000a). Concernant le moment du premier oestrus saisonnier, un degré élevé de synchronisme peut être observé entre les femelles. Signe de l'association de ce synchronisme et d'une fertilité exceptionnelle, la plupart des femelles sont fécondées au premier oestrus puisque dans les élevages de l'hémisphère Sud, 91,4 \% des adultes sont gestantes avec une date de conception antérieure au ler mai (soit le $1^{\mathrm{er}}$ novembre dans l'hémisphère Nord) (Audige et al 1999). Il est à noter que, chez les bichettes, le moment du premier oestrus semble décalé d'environ trois semaines par rapport à celui des adultes. D'une manière générale, il est très difficile de mener des observations du comportement d'oestrus chez les cervidés. Plusieurs types de comportements peuvent être observés durant la séquence pré-copulatoire (Guinness et al 1971). Le premier signe de venue en chaleur chez la biche semble être la relative proximité du mâle qui se tient à moins de $15 \mathrm{~m}$ de la femelle. D'après Guinness et collaborateurs, le mâle semble « garder » la femelle. Progressivement, l'intérêt du mâle pour la femelle augmente. La biche réagit aux sollicitations du mâle par la fuite. Lorsque la femelle se couche, le mâle l'incite à se relever par des mouvements de tête sur l'arrière main. Progressivement, les réactions de fuite de la femelle diminuent et la biche au lieu de fuir, s'immobilise. L'accouplement suit généralement immédiatement. La durée de la période d'oestrus chez la biche élaphe est de l'ordre de 24 heures.

En absence d'accouplements, les femelles sont polyo-oestriennes. Le suivi de la progestéronémie montre que les femelles peuvent présenter 5 à 10 cycles ovulatoires dont la durée moyenne est d'environ 19 jours chez l'élaphe (Guinness et al 1971, Asher et al 2000, Garcia et al 2002). Par ailleurs, il semble que la durée des cycles puisse s'allonger au fur et à mesure de leur succession (Guiness et al 1971). Ainsi, chez la femelle élaphe et sous nos latitudes, une succession de cycles oestriens peut être observée sur une période allant de septembre à mars. L'entrée en saison sexuelle se caractérise par une augmentation discrète des niveaux de progestérone $(<1 \mathrm{ng} / \mathrm{ml})$ suite à l'ovulation silencieuse. Les 
cycles qui suivent le premier oestrus sont caractérisés par des niveaux de progestérone élevés ( $>3 \mathrm{ng} / \mathrm{ml}$ ) (figure 2a).

Entre les espèces, des variations du moment du rut, de la durée et du nombre de cycles ainsi que de la durée de gestation peuvent être observées (tableau 2). Chez les femelles sika, renne ou père David, les durées de cycles sont assez comparables à ce qui peut être observé chez l'élaphe (sika : père David : Curlewis et al 1988). Chez le daim, la femelle présente des cycles quelque peu plus longs $(22,4$ jours). La durée de la saison sexuelle est influencée par l'âge des femelles et peut varier de 65 à 135 jours, ce qui correspond à 3 ou 6 cycles par femelle (Asher 1985).

\section{b) Croissance folliculaire}

\section{- Période d'activité sexuelle}

Chez de nombreuses espèces de cervidés, les femelles sont mono-ovulantes, c'est-à-dire que pendant la saison et au cours du cycle oestral, un seul follicule dit dominant parvient à l'ovulation. Chez la biche élaphe, l'étude de la croissance folliculaire par suivi échographique proposée par Asher et collaborateurs montre qu'en saison sexuelle, la taille moyenne de la population de follicules varie quotidiennement au cours du Liu et al 2002, renne : Ropstad 2000,

cycle mais que par contre, le nombre total de follicules de plus de $3 \mathrm{~mm}$ de diamètre ne variait que de façon discrète $(1,8$ à 3,4$)$. Cette étude montre également que sur une durée de cycle d'environ 19 jours, une à trois vagues d'émergence et de disparition d'un plus gros follicule (1 à 3 follicules dominants en croissance selon les animaux) pouvaient être observées (figure 3a). Suite à la régression ou ovulation de cet unique gros follicule, de nouveaux follicules émergent alors, suggérant un effet dit de " dominance » de ce follicule (figure $3 a)$. Les petits follicules ( $3 \mathrm{~mm}$ de diamètre) sont donc présents surtout en début de cycle après disparition (ovulation) du précédent follicule dominant (Asher et al 1997). La dynamique de la croissance folliculaire semble similaire chez la daine (Asher et al 1999).

Les variations hormonales au cours du cycle ont été bien caractérisées chez la femelle du renne ou chez le daim et sont similaires à ce qui peut être observé chez la brebis (renne : Ropstad et al 1995, daim : Asher et al 1986, Asher et al 1988, Asher et al 1990). Le cycle oestral peut être caractérisé par la succession d'une phase folliculaire qui correspond au recrutement de follicules jusqu'à l'ovulation et d'une phase lutéale (lutéotrope et lutéolytique) qui débute après l'ovulation jusqu'à la régression du corps jaune. La phase folliculaire fait suite à la chute des concentrations de progestérone, et est

Figure 2. (a) Suivi saisonnier de l'activité lutéale chez une biche élaphe par mesure de progestérone sous une latitude élevée de l'hémisphère nord (adapté de Asher et al 2000). La flèche pleine désigne le moment de l'ovulation silencieuse. (b) Evolution des taux plasmatiques de $\mathrm{LH}$ chez la biche élaphe ovariectomisée (o) et ovariectomisée et supplémentée en oestradiol (o) (adapté de Meikle et Fisher 1996).

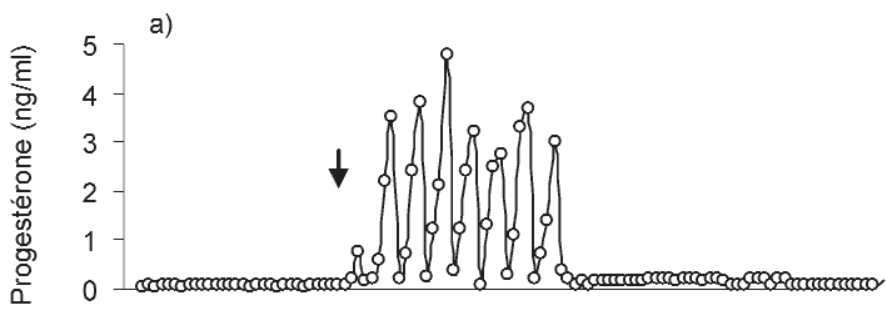

b)

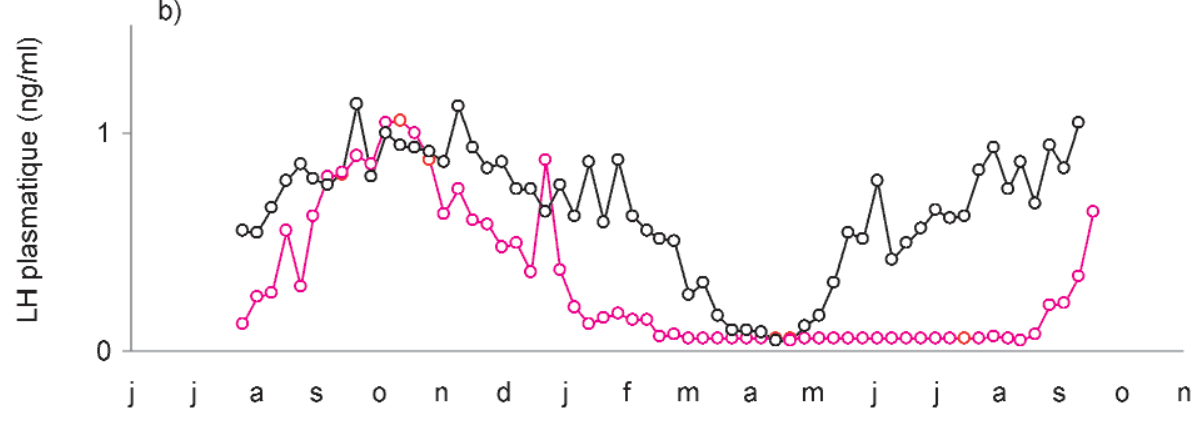

associée à une « reprise » de croissance folliculaire. Au cours de cette phase (environ 3 jours chez le renne), les niveaux d'oestradiol augmentent sous l'effet des gonadotrophines pour atteindre des valeurs maximales dans les 3 heures qui précèdent le pic pré-ovulatoire de LH (Ropstad et al 1995). Chez la biche élaphe, les niveaux d'oestradiol plasmatiques peuvent atteindre des valeurs très élevées (moyenne $89 \mathrm{pg} / \mathrm{ml}$ ) le jour de l'oestrus (Kelly et al 1985). Chez la daine, l'augmentation d'oestradiol qui précède le moment de l'oestrus n'est pas significative et les valeurs maximales semblent atteintes 2 heures après ce dernier (Asher et al 1986).

Chez le cerf de Virginie dont la durée de cycle est plus longue, cette augmentation semble intervenir plus tôt (3-4 jours) vis-à-vis du moment d'oestrus (Plotka et al 1980). Il est à noter que chez la daine, une forte augmentation des concentrations d'androstènedione peut être observée au moment de l'oestrus reflétant probablement l'intensification de la stéroïdogenèse folliculaire sous l'effet de la LH (Asher et al 1986). Chez la biche élaphe supplémentée en progestérone par pose d'implants intra-vaginaux de type CIDR (Controlled Internal Drug Releasing, $0,3 \mathrm{~g})$, il a été possible de caractériser la phase folliculaire à différents moments à partir du retrait de l'implant. Le moment d'apparition du pic préovulatoire intervient dans ce cas $44,5 \pm 6,6 \mathrm{~h}$ après le retrait de l'implant (McLeod et al 2001a). Il semble dans ce cas que les niveaux d'oestradiol dans le fluide folliculaire, l'activité aromatase des cellules de granulosa et leur production d'AMPc (mesurée in vitro) augmentent à partir du retrait du CIDR pour atteindre un maximum $24 \mathrm{~h}$ après celui-ci et diminuer ensuite (36 h).

La phase lutéale débute après la rupture folliculaire et est associée à une élévation de la progestérone. Chez l'élaphe, l'augmentation débute au $3-4 \mathrm{e}$ jour après l'oestrus et atteint un maximum au 10-16 $\mathrm{e}^{\mathrm{e}}$ jour (Asher et al 1997). Chez les biches élaphe dont l'oestrus est synchronisé, les niveaux de progestérone chutent à des valeurs inférieures à $1 \mathrm{ng} / \mathrm{ml}$ entre le $18^{\mathrm{e}}$ et le $25^{\mathrm{e}}$ jour suivant le retrait du traitement progestagène. Il est bien établi chez la plupart des ruminants que les sécrétions endogènes de prostaglandines produites essentiellement par l'utérus sont responsables de la lutéolyse en fin de cycle non fécond. Ceci a pu être confirmé chez la daine, puisque l'hystérectomie réalisée au $13^{\mathrm{e}}$ jour du cycle 
Tableau 2. Origines géographiques et caractéristiques de reproduction de différentes espèces ou sous-espèces de cervidés.

\begin{tabular}{|c|c|c|c|c|c|}
\hline $\begin{array}{l}\text { Nom scientifique } \\
\text { Genre, espèces, } \\
\text { sous-espèces }\end{array}$ & $\begin{array}{c}\text { Origine } \\
\text { géographique }\end{array}$ & Période du rut ${ }^{1}$ & $\begin{array}{l}\text { Durée du cycle } \\
\text { chez la femelle }\end{array}$ & $\begin{array}{c}\text { Durée } \\
\text { de la gestation }\end{array}$ & Références \\
\hline Axis axis & Inde & peu saisonnée & $\begin{array}{c}18 \mathrm{j} \\
19,3 \mathrm{j}\end{array}$ & $\begin{array}{l}238-242 \mathrm{j} \\
234,5 \mathrm{j}\end{array}$ & $\begin{array}{l}\text { Loudon et Curlewis } 1988 \\
\text { Chapple et al } 1993 \\
\text { Mylrea et al } 1999\end{array}$ \\
\hline Capreolus capreolus & $\begin{array}{c}\text { Europe } \\
\text { et Asie Mineure }\end{array}$ & Juil-Août & $-{ }^{*}$ & $290-300 j^{*}$ & Aitken 1974 \\
\hline Cervus elaphus scoticus & Europe & Sept-Oct & $19 \mathrm{j}$ & $231 \mathrm{j}$ & $\begin{array}{l}\text { De Vos } 1982 \\
\text { Guiness et al } 1971\end{array}$ \\
\hline Cervus eldi thamin & $\begin{array}{c}\text { Birmanie, } \\
\text { Tenasserim } \\
\text { et partie adjacente } \\
\text { de la Thaïlande } \\
\end{array}$ & Fév-Mars & $21,5 \mathrm{j}$ & $236-246$ j & $\begin{array}{l}\text { Prescott } 1987 \\
\text { Yuan et al } 1998 \\
\text { Montfort et al } 1990\end{array}$ \\
\hline Cervus nippon & $\begin{array}{c}\text { Japon, archipels } \\
\text { adjacents, Corée, } \\
\text { Chine... }\end{array}$ & Oct-Nov & $19 \mathrm{j}$ & $226-234$ j & $\begin{array}{l}\text { Bing-Tsan, Liu et al } 2002 \\
\text { Hamasaki et al } 2001 \\
\text { Miura } 1984\end{array}$ \\
\hline Dama dama dama & $\begin{array}{c}\text { Europe } \\
\text { et Asie Mineure }\end{array}$ & Oct-Nov & $21-22 j$ & $\begin{array}{l}229-234 j \\
234 j\end{array}$ & $\begin{array}{l}\text { Gosch, Fischer } 1989 \\
\text { Asher et al } 1985\end{array}$ \\
\hline Elaphurus davidianus & Chine & Juil-Août & $19,5 \mathrm{j}$ & $280-282$ j & $\begin{array}{l}\text { Curlewis et al } 1988 \\
\text { Brinklow, Loudon } 1993\end{array}$ \\
\hline $\begin{array}{l}\text { Odocoileus virginianus } \\
\text { virginianus }\end{array}$ & $\begin{array}{c}\text { Virginie } \\
\text { et Etats adjacents }\end{array}$ & Nov & $28 \mathrm{j}$ & $200 \mathrm{j}$ & Plotka et al 1977a \\
\hline $\begin{array}{l}\text { Rangifer tarandus } \\
\text { tarandus }\end{array}$ & Norvège et Russie & Sept-Oct & $19,4 j$ & $225-235$ j & Ropstad 2000 \\
\hline Muntiacus reevesi & $\begin{array}{l}\text { Chine du Sud-Est, } \\
\text { Taïwan }\end{array}$ & peu saisonnée & $?$ & $210 j$ & Chapman et Harris 1991 \\
\hline
\end{tabular}

${ }^{1}$ Sous des latitudes élevées de l'hémisphère nord.

* Espèce mono-oestrienne présentant une diapause et implantation embryonnaire différée.

abolit la cyclicité (Asher et al 1988). Comme pour la vache ou la brebis, la lutéolyse est associée (au 18 e jour chez la biche) à des pulses synchrones d'ocytocine et de PGF2 $\alpha$ (Bainbridge et al 1996, Bainbridge et Jabbour 1997). Il est à noter que chez le daim, le synchronisme des pulses d'ocytocine et de PGF $2 \alpha$ (mesurée par les niveaux des métabolites de PGF2 $\alpha$ ) n'est pas aussi évident (Asher et al 1988). Chez l'élaphe, l'injection d'ocytocine exogène provoque la sécrétion de PGF2 $\alpha$ (Flint et al 1994) et celle d'un analogue de PGF2 $\alpha$ libère 1'ocytocine (Flint et al 1991) suggérant l'existence d'un feedback positif. Ce rétrocontrôle positif est activé en fin de cycle du fait de l'augmentation des niveaux d'oestradiol qui entraînent une sensibilité plus élevée de l'endomètre à l'ocytocine d'origine ovarienne et/ou extra-ovarienne (Bainbridge et al 1996, Bainbridge et Jabbour 1999). La progestérone et l'oestradiol semblent intervenir au niveau des cellules de l'endomètre dans la régulation de l'expression des récepteurs à l'ocytocine et par conséquent moduler la sensibilité du système au cours du cycle (Spencer et Bazer 2004).

\section{- Période de repos sexuel}

Les observations faites en dehors de la saison sexuelle chez la femelle wapiti (Cervus elaphus canadensis) ont confirmé des variations du nombre total de follicules observés sur l'ovaire. Des pics d'apparition et de disparition de follicules suggèrent une vague de croissance folliculaire tous les 7 jours associée à l'émergence d'un follicule dominant (McCorkell et al 2004). En comparaison, avec ce qui peut être observé en saison sexuelle, le nombre total de follicules n'est pas diminué durant l'anoestrus (figure 3b). Par contre, traduisant certainement les modifications des niveaux d'hormones gona- dotropes, la durée de vie, la taille moyenne ainsi que la taille maximale atteinte par ces follicules sont sensiblement inférieures aux observations faites pendant la saison sexuelle (Asher et al 1997, Mac Corkell et al 2004).

\section{c) Hormones gonadotropes}

Comme nous l'avons évoqué chez le mâle, les variations d'activité sexuelle résultent de changements de sécrétions d'hormones gonadotropes. Les études des mécanismes responsables de ces variations d'activité ont été réalisées principalement chez les femelles du cerf élaphe et du daim.

Chez les biches ovariectomisées et supplémentées ou non en oestradiol, des différences importantes peuvent être observées en fonction de la période de reproduction. La concentration de LH est élevée durant la période des jours courts et faible pendant les jours 
Figure 3. Profils de croissance folliculaire déterminés par suivi échographique des fol-

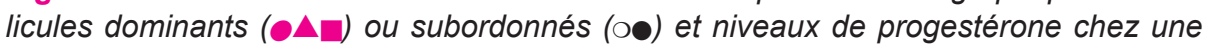
biche élaphe durant le mois de (a) décembre et (b) mai.

*Désigne la rupture du follicule (adapté de Asher et al 1997).

a)

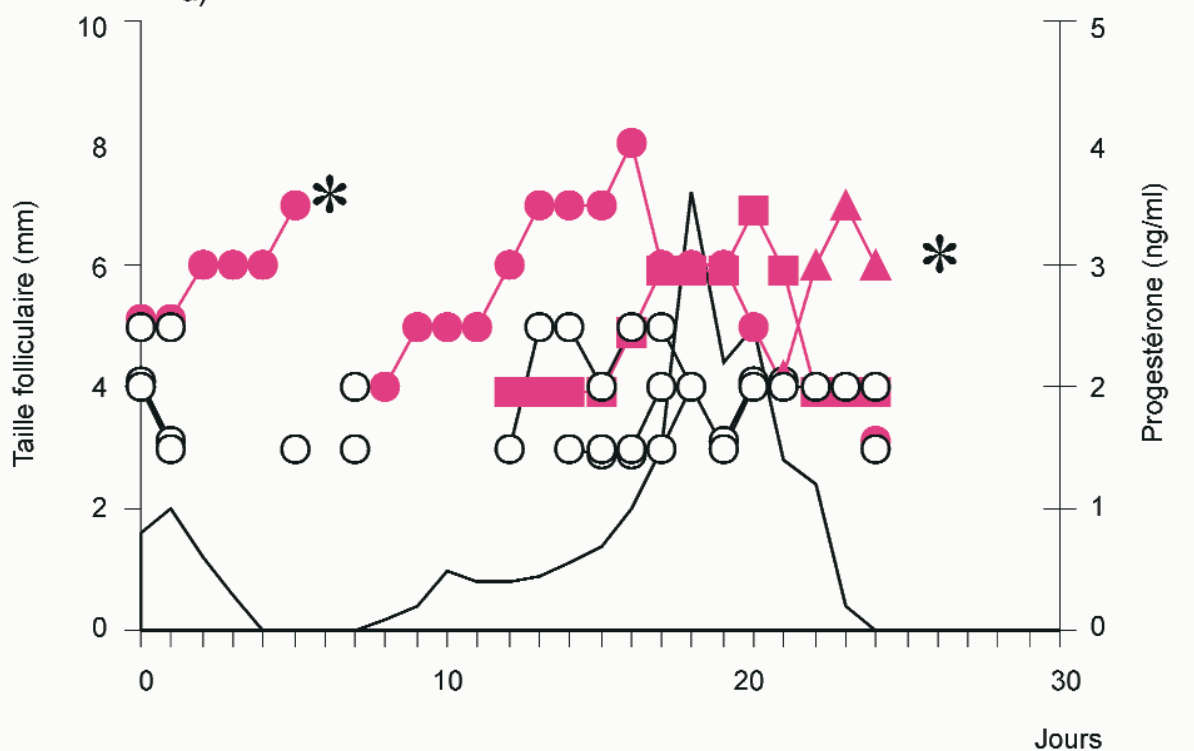

b)

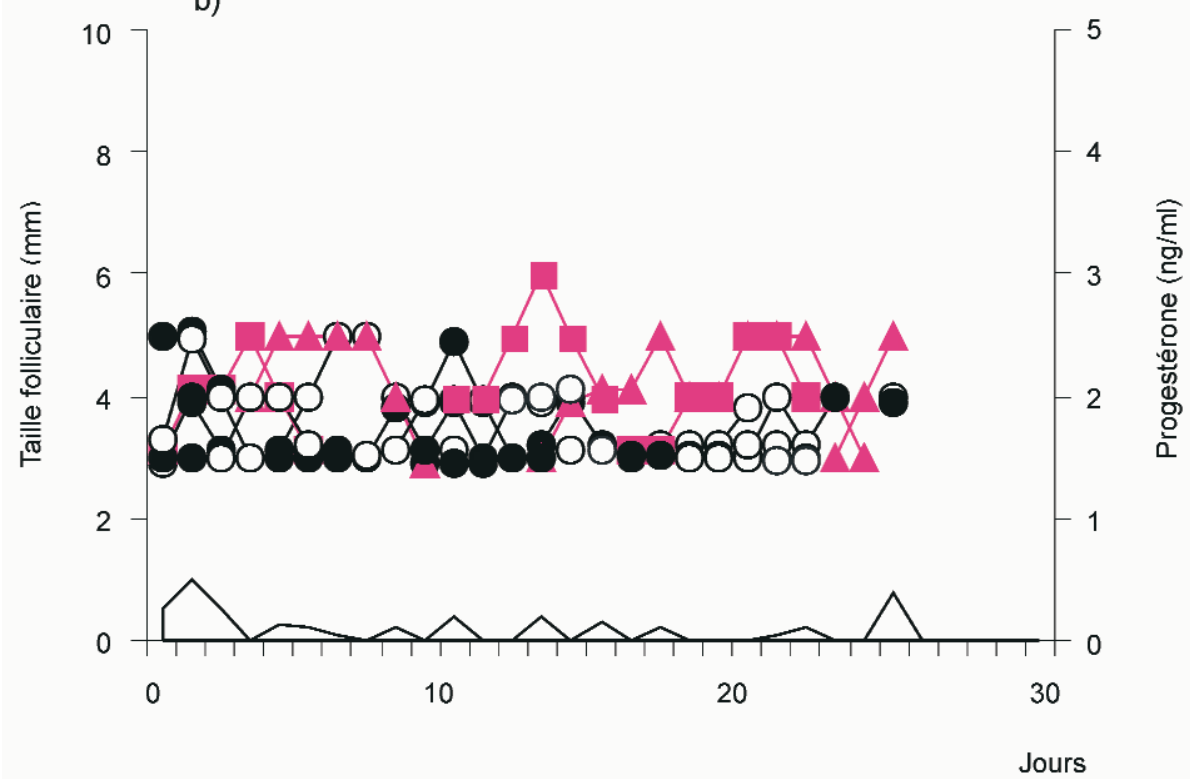

longs et à plus forte raison en absence d'oestradiol (Meikle et Fisher 1996). La pulsatilité de LH chez les femelles ovariectomisées est significativement réduite entre la période d'activité et de repos sexuelle (4 vs 1 pulse/h respectivement, figure $2 b$ ). De même, l'amplitude des pulses semble réduite (Anderson et Barrell 1998a). Il semble que l'oestradiol exerce un effet inhibiteur sur la libération de LH (figure 2b). La réponse à l'administration de $10 \mu \mathrm{g}$ de GnRH mesurée par les niveaux de LH en saison sexuelle est supérieure à celle observée en période d'anoestrus chez ces femelles. Il est à noter que les

femelles ayant reçu de l'oestradiol présentent en saison sexuelle des concentrations de $\mathrm{LH}$ en réponse au GnRH près de 2 fois plus élevées par rapport aux biches ovariectomisées (Meikle et Fisher 1996). Aussi il semble que des mécanismes à la fois dépendants et indépendants des stérö̈des soient impliqués dans les modifications saisonnières de sécrétion de LH.

\section{d) Contrôle de la saisonnalité}

A l'instar de ce que nous avons déjà décrit chez le mâle, les variations d'activité sexuelle sont influencées par la photopériode (Webster et Barrell
1985). Chez l'élaphe, il est par exemple, possible d'avancer le moment du premier oestrus d'un mois en soumettant les femelles à une photopériode courte ( $8 \mathrm{~h}$ de lumière par jour) à partir du solstice d'été. Un résultat identique peut être obtenu par administration de mélatonine. Dans ces deux cas, les niveaux de prolactine sont significativement diminués en comparaison d'animaux témoins et la mue du pelage est avancée (Webster et Barell 1985). Chez la daine, l'administration de mélatonine sous forme d'implants sous cutanés en été permet également l'avancée de la saison sexuelle (Asher et al 1988). Il semble que l'entraînement photopériodique chez les femelles de cervidés soit assuré par des mécanismes similaires à ceux décrits chez le mâle.

Le rôle des hormones thyroïdiennes en fin de la saison sexuelle a également fait l'objet d'études. Chez la femelle élaphe thyroïdectomisée, un allongement de la durée de la saison sexuelle peut être observé. La supplémentation en hormone T4 permet de rétablir une durée d'activité sexuelle comparable aux témoins. Comme nous l'avons vu plus haut, chez les femelles ovariectemisées supplémentées ou non en oestradiol, les niveaux et la pulsatilité de LH sont faibles en dehors de la saison sexuelle. En présence d'oestradiol, des profils de concentration de LH identiques peuvent être observés entre les femelles ayant subi une thyroïdectomie ou leur témoins. Par contre, en absence d'oestradiol, les concentrations de LH sont augmentées chez les femelles thyroïdectomisées à la période correspondant à la sortie de la saison sexuelle. Ainsi les hormones thyroïdiennes semblent nécessaires à l'expression de profils de reproduction saisonniers (fin de saison sexuelle) en exerçant un effet négatif sur les sécrétions de LH indépendamment de l'oestradiol (Anderson et Barrell 1998b). e) Cas particulier : espèces subtropicales

Chez les femelles du cerf axis (Axis axis) placées sous des latitudes élevées, la cyclicité est observée tout au long de l'année. La durée moyenne des cycles est de 18 jours (Mylrea et al 1999). Pour cette espèce, à l'instar de ce qui a pu être décrit chez le mâle, il semble que le signal photopériodique n'influence pas la fonction de reproduction.

Dans son milieu d'origine (Philippines, Indonésie, Chine du sud, Birmanie, Inde...), le cerf sambar 
Figure 4. Comparaison du taux de croissance fotal au cours de la gestation chez l'élaphe (-) et chez la brebis portant 2 fœtus (-) (d'après les données de Robinson et al 1977, Adam et al 1988).

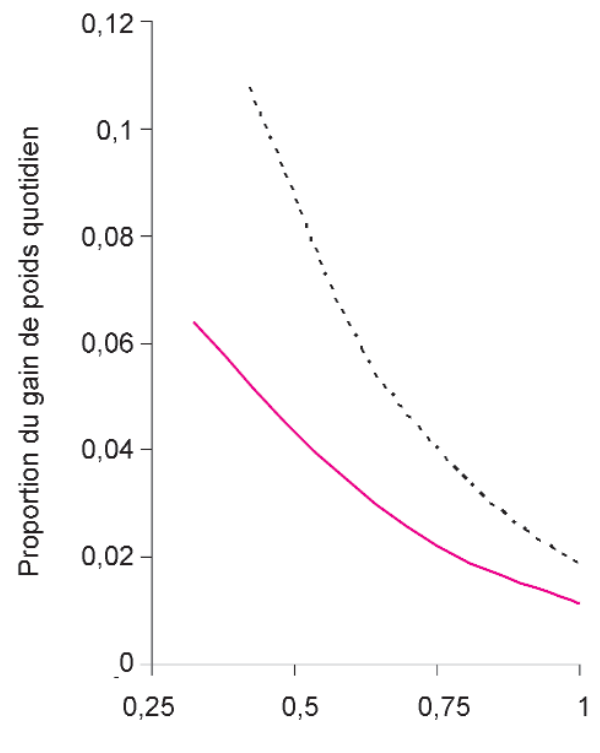

Proportion de la gestation

(Cervus unicolor) se reproduit toute l'année. Placée sous des latitudes élevées, la femelle présente un nombre très variable de cycles dont la durée moyenne est de 17 jours (Asher et al 1997). Si, chez la biche élaphe, les concentrations de prolactine dans le sang périphérique, montrent des variations annuelles marquées avec augmentation et diminution concomitantes des variations de la durée du jour (Asher et al 2000a, Garcia et al 2002) il n'en est pas de même chez la femelle sambar (Asher et al 1997). Etonnamment, en comparaison de ce qui peut être observé chez l'élaphe, ou d'autres espèces originaires des zones saisonnées ou non, les mesures de prolactine chez la femelle sambar sous des latitudes élevées ne présentent pas de variations annuelles marquées. Alors que ces variations annuelles sont fortes chez l'élaphe $(2 \mathrm{ng} / \mathrm{ml}$ en hiver et 120$160 \mathrm{ng} / \mathrm{ml}$ en été), une augmentation discrète peut être observée chez le sambar $(<2 \mathrm{ng} / \mathrm{ml}$ en hiver et $10 \mathrm{ng} / \mathrm{ml}$ en été). Pourtant, la capacité de réponse à l'injection de TRH (Thyrotropin Releasing Hormone) sur la libération de prolactine mesurée dans le sang périphérique semble similaire entre les deux espèces (Asher et al 1997). Ces données pourraient traduire des différences importantes de l'intégration du signal photopériodique pour cette espèce.

\section{4 / Gestation}

Il existe des variations relativement importantes de la durée de gestation au sein de la famille des cervidés (tableau 2). La durée de gestation observée chez le chevreuil (de l'ordre de 300 jours) est un cas particulier puisqu'il s'agit d'une espèce présentant une implantation embryonnaire différée.

\section{a) Développement embryonnaire}

Après fécondation, l'embryon du cerf élaphe atteint le stade blastocyste éclos vers le 8ème jour et semble rester sphérique au moins jusqu'au $11^{\mathrm{e}}$ jour (Peterson et al 1997, Demmers et al 2000). Au 14e jour les embryons sont toujours sphériques, localisés dans la corne ipsilatérale à l'ovulation et commencent leur expansion. Au 16 $\mathrm{e}$ jour le trophoblaste s'étend en direction de la corne contra latérale, le disque embryonnaire devient proéminent. L'expansion du trophoblaste se poursuit formant un long filament de près de $30 \mathrm{~cm}$ vers le $21-22^{\mathrm{e}}$ jour. C'est à ce stade que l'accolement de l'embryon à la paroi semble intervenir. Le tube neural est alors déjà formé, restant ouvert à ses deux extrémités et des somites peuvent être visualisées. Le début de la placentation peut être observé avec la formation des caroncules puis de plaques trophoblastiques et enfin des cotylédons (41e jour) (McMahon et al 1997). La placentation des cervidés est de type synepitheliochoriale et oligocotylédonaire puisque selon les espèces, le nombre moyen de cotylédons par placenta se situe entre 4 et 6 ( 8 chez l'élaphe), contrastant avec ce qui peut être observé chez les bovins, ovins ou caprins dont le nombre est supérieur à
10 (Benirschke non publié). Chez l'élaphe, le développement de l'embryon, apprécié par la croissance foetale (gain de poids du fotus, g/jour) au cours de la gestation est très inférieur à ce qui peut être observé chez la brebis (figure 4). Dans le cas de la brebis mettant bas 2 agneaux, la production fotale en 145 jours est de près de $9 \mathrm{~kg}$ tandis que chez la biche, elle n'est que de $7,5 \mathrm{~kg}$ en 233 jours (Adam et al 1988). Le gain de poids atteint au maximum $86 \mathrm{~g} /$ jour en fin de gestation chez la biche contre 168, 217 ou même 250 $\mathrm{g} /$ jour chez la brebis selon le nombre de fotus (2, 3, ou 4 respectivement) (Robinson et al 1977, Adam et al 1988). Il est à noter que chez la biche, le développement placentaire se poursuit tout au long de la gestation, atteignant $7 \mathrm{~g} /$ jour à l'approche de la parturition. Le sexe influence significativement le poids du foetus et du placenta (Adam et al 1988). L'âge des reproductrices (figure 5) et leur distribution géographique (densité de population, richesse des pâtures...) influencent la fertilité mais également le poids des faons (Guinness et al 1978).

\section{b) Modifications hormonales, corps jaune gestatif}

Afin de permettre l'implantation de l'embryon (vers le 24e jour), il est nécessaire que les niveaux de progestérone demeurent élevés (hyperplasie de l'endomètre). Dans le cas de la gestation, les pulses synchrones de PGF $2 \alpha$ et d'ocytocine qui sont à l'origine de la régression fonctionnelle du corps jaune Figure 5. Influence de l'âge des biches sur la fertilité et le poids de mise bas des faons (Guinness et al 1978).

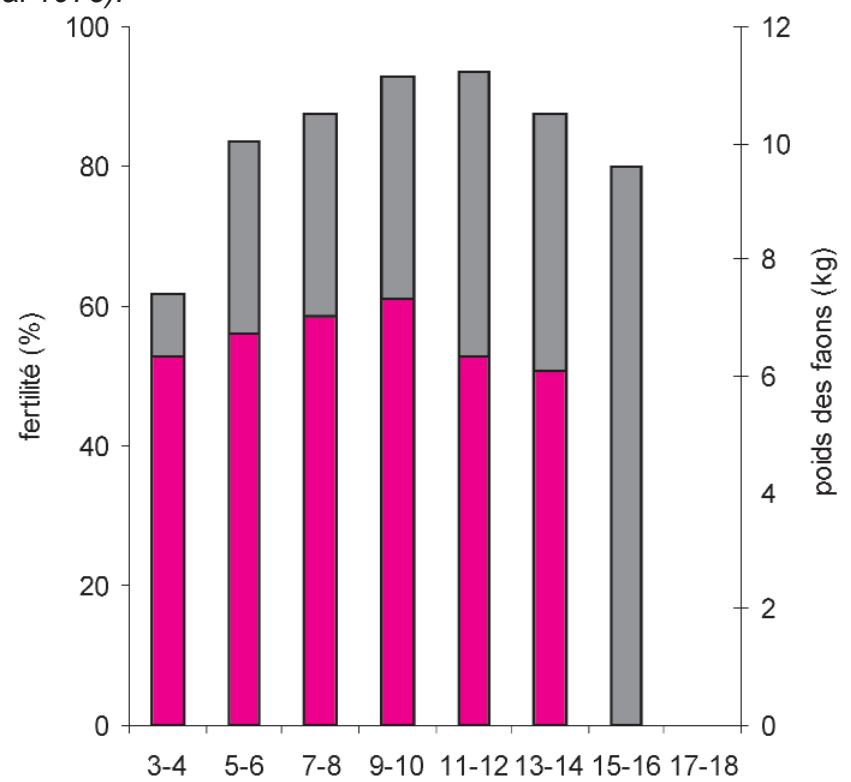

$\square \%$ fertilité age (ans)

$\square$ poids des faons 
Figure 6. Représentation schématique illustrant la régulation hormonale de la lutéolyse par l'endomètre en absence a) ou présence b) de signal embryonnaire chez la biche élaphe. Chez la femelle du chevreuil, le corps jaune se maintient sans signal embryonnaire. PGF2 $\alpha$ : prostaglandine $F 2 \alpha$; IFN-tau : interferon tau ; OTR : récepteur à l'ocytocine.

a)

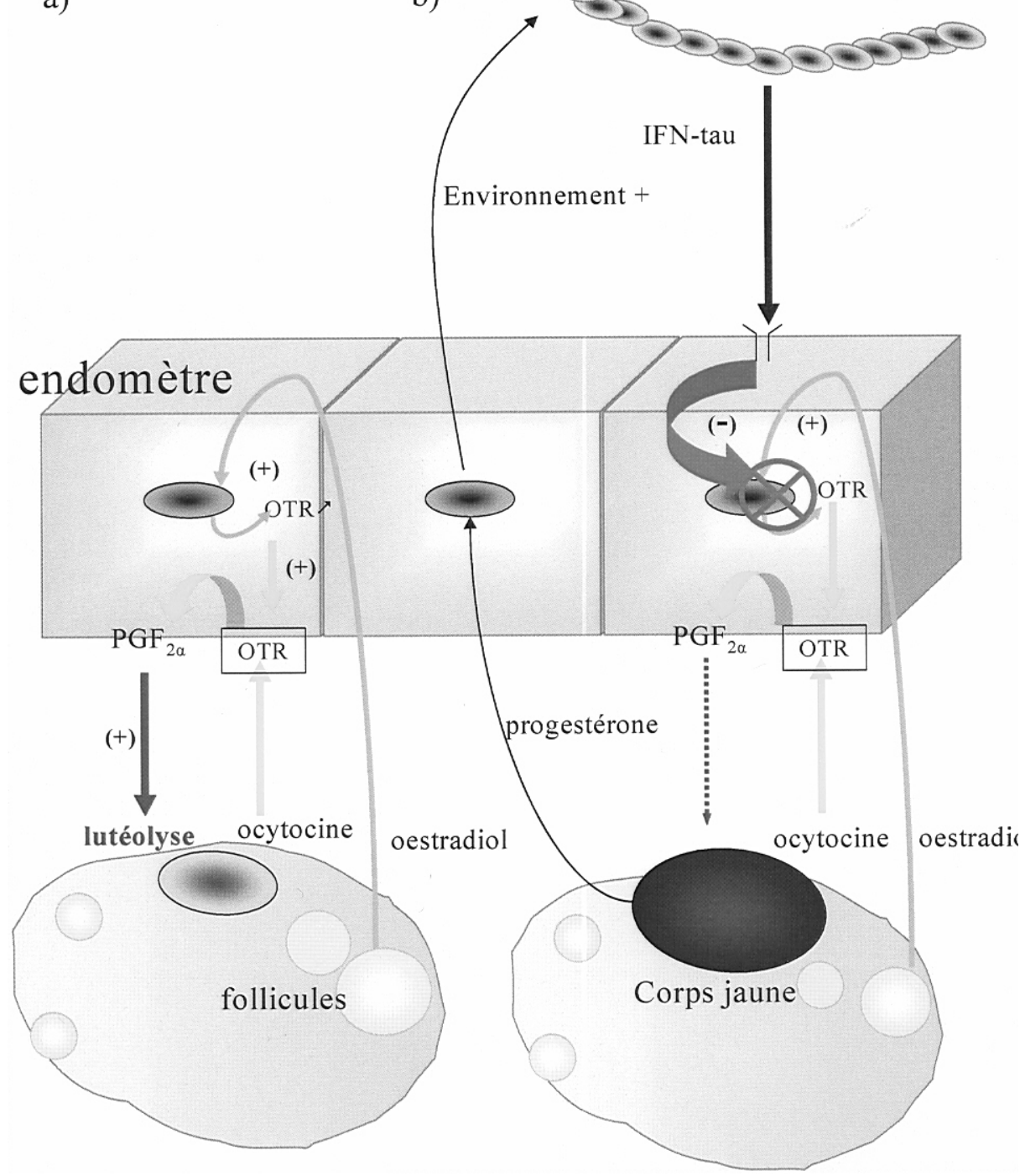

(voir plus haut) ne sont pas observés en fin de cycle (Bainbridge et Jabbour, 1997). Des mécanismes antilutéolytiques permettant d'empêcher la libération de prostaglandines sont donc mis en place, en réponse aux signaux embryonnaires. Chez les ruminants, des sécrétions d'interféron sont produites par le trophoblaste de façon précoce et transitoire. Ces molécules possèdent des propriétés antilutéolytiques, antivirales, antiprolifératives et immunomodulatrices qui sont nécessaires au maintien de la gestation (Demmers et al 2001). Il semble qu'il en soit de même chez les cervidés puisque chez l'élaphe, l'injection d'interféron de type 1 , permet la suppression des pulses de PGF $2 \alpha$ en fin de cycle (Bainbridge et Jabbour 1997, Bainbridge et al 1996). au niveau de l'endomètre entraînant la diminution de l'expression des récepteurs à l'ocytocine et par conséquent les sécrétions endométriales de PGF $2 \alpha$ (Demmers et al 2000, 2001). La lutéolyse est ainsi inhibée permettant le maintien des sécrétions de progestérone et l'implantation embryonnaire (figure 6).

Selon nos propres observations, les niveaux de progestérone sont plus ou moins constants pendant la gestation, variant de 3 à plus de $8 \mathrm{ng} / \mathrm{ml}$ selon les femelles élaphe (3 à $5 \mathrm{ng} / \mathrm{ml}$ selon Adam et al 1985). Les niveaux de progestérone ne diminuent que peu de temps avant la parturition (Kelly et al 1982, Adam et al 1985). Il est à noter que, selon les auteurs, des différences importantes de concentrations de progestérone peuvent être observées au sein d'une même espèce et pour les mêmes états physiologiques. A la lumière de l'étude menée chez le daim par Asher et al (1989b), il semble que ces différences puissent s'expliquer par les sécrétions de la glande corticosurrénale. En effet, l'injection d'un analogue d'ACTH (Adrenal Cortex Trophic Hormone) à des femelles impubères ou pubères, et ovariectomisées ou non, provoque l'augmentation de 4 à 10 fois de la concentration de progestérone périphérique. Il est donc probable que le stress et les sécrétions coticosurrénaliennes associées soient un facteur important de variations de progestéronémie.

La contribution placentaire dans l'établissement de ces concentrations n'a pu être mise en évidence chez l'élaphe dans le premier tiers de la gestation. Il semble que les sécrétions lutéales de progestérone demeurent primordiales pour le maintien de la gestation au moins jusqu'au 75e jour (Asher et al 1996a). En effet, l'ovariectomie ou la lutectomie réalisées au $30^{e}$ jour de gestation provoquent l'avortement dans les dix jours qui suivent. Quand elles sont réalisées au $75^{\mathrm{e}}$ jour, l'avortement a également lieu mais peut être légèrement retardé (jusqu'à 25 jours plus tard). Une chute importante de progestéronémie est alors associée. L'injection d'un analogue de prostaglandine $(500 \mu \mathrm{g}$ cloprostenol) ne provoque pas systématiquement l'avortement, suggérant une inefficacité de cette molécule dans la lutéolyse complète du corps jaune durant cette période. Chez le cerf de Virginie, l'ovariectomie induit l'avortement quelque soit le stade de la gestation indiquant que la progestérone lutéale est également primordiale pour le maintien de la gesta- 
tion chez cette espèce (Plotka et al 1982). Il n'en est pas de même chez le renne (Sjaastad et al 1990), ce qui suggère que des différences importantes dans les contributions lutéale, foetoplacentaire ou corticosurrénalienne de sécrétions de progestérone peuvent être observées entre les espèces.

Des variations de concentrations d'oestrogènes peuvent également être observées au cours de la gestation. Après synchronisation de l'oestrus, les niveaux d'oestradiol diminuent pour atteindre des valeurs de l'ordre de 5 à $10 \mathrm{pg} / \mathrm{ml}$ entre 160-190 jours de gestation (Kelly et al 1982). Il en est de même chez des femelles témoins (non gestantes, non cycliques). Il est probable que cette diminution reflète la baisse d'activité ovarienne, comme en témoignent les faibles concentrations de LH durant cette période. Par contre, dans le cas des femelles gestantes, une augmentation significative des concentrations plasmatiques d'oestradiol $(35 \mathrm{pg} / \mathrm{ml})$ précède la parturition (Kelly et al 1982). Des observations similaires ont été reportées chez le cerf de Virginie (Harder et Woolf 1976, Plotka et al 1977b). Chez la brebis, les concentrations plasmatiques de sulfate d'oestrone augmentent à partir du $50^{\mathrm{e}}$ jour de gestation pour atteindre un pic peu de temps avant la mise bas. Il semble en être de même chez les cervidés puisque chez le daim, les niveaux semblent augmenter de façon significative au 90e jour de la gestation (Willard et al 1998). Chez le cerf d'Eld, les concentrations urinaires des conjugués d'oestrone varient également au cours de la gestation. Elles augmentent tout d'abord de façon précoce avec un pic entre la $29^{\mathrm{e}}$ et la $19^{\mathrm{e}}$ semaine qui précède le terme. Un second pic, plus important (40 fois les niveaux de base) peut être observé durant les 5 dernières semaines de la gestation (Monfort et al 1990). L'origine ovarienne ou foetoplacentaire de ces sécrétions n'a pas été déterminée chez les cervidés.

D'autres molécules sont exprimées précocement et spécifiquement dans le cas de la gestation. Chez la vache, la PAG-I (Pregnancy-Associated Glycoprotein) initialement dénommée PSPB (Pregnancy-Specific Protein B) ou encore PSP60 (Pregnancy Serum Protein of $60 \mathrm{kDa}$ ) est une glycoprotéine synthétisée par les cellules binucléées du trophoblaste. Plusieurs variants moléculaires des transcrits PAGs ont été identifiés chez les bovins ovins ou caprins. Il semble que l'expression de ces différentes formes varie entre les cellules du placenta (trophectoderme / cellules binucléées) et dans le temps (Green et al 2000). La fonction précise des PAGs dont la structure est apparentée à la famille des proteinases à aspartate n'est pas connue (Xie et al 1997, Beckers et al 1999). Chez le cerf de Virginie (Odocoileus virginianus), 9 séquences de transcrits de PAG ont pu être identifiées dans le placenta (Vawter et al 2003, non publié). Si leur fonction n'est pas connue, l'immunoréactivité de ces molécules peut être mesurée et permet le diagnostique précoce de gestation. Elle est détectée dès le $24 \mathrm{e}$ jour chez la vache, et entre le $27 \mathrm{e}$ et le $33^{\mathrm{e}}$ jour chez les cervidés (Willard et al 1998). Le dosage des PAGs est un complément précieux au diagnostique de gestation par échographie et a pu être appliqué avec succès chez les cervidés comme le daim (Willard et al 1998, Willard et al 1999), le cerf sika (Willard et al 1996), ou encore le renne (Vahtiala et al 2004). Chez les cervidés, les niveaux périphériques décelés semblent toujours très inférieurs à ce qui peut être observé chez les caprins, ovins ou bovins. Bien que les PAGs possèdent une structure relativement conservée chez les mammifères, il est possible que l'immunoréactivité des PAGs ou PSPB diffère quelque peu entre les espèces (Huang et al 1999) et que l'utilisation d'anticorps non spécifiques puisse fausser les niveaux détectés. De même, l'expression temporelle des molécules (expression précoce notamment) peut être différente d'une espèce à l'autre.

\section{c) Un cas particulier, le chevreuil}

Le chevreuil se distingue de la majorité des cervidés originaires des zones tempérées dans la mesure où la période du rut se situe en juillet et août. Durant cette période, la chevrette (femelle du chevreuil) ne présente qu'un cycle ovulatoire. L'ovulation est souvent multiple puisque le nombre moyen de corps jaunes par femelle s'élève à $2,13 \pm 0,13$ $(\mathrm{m} \pm \mathrm{SEM}, \mathrm{n}=15$ d'après Lambert et al 2001), permettant la mise bas très fréquente de 2 voire 3 faons par femelle (1,8 en moyenne). Cette espèce est par conséquent dite poly-ovulante mono-oestrienne. L'administration de mélatonine exogène sous forme d'implants sous cutanés (du mois d'avril au mois d'août) permet d'avancer le moment de l'ovulation de plus de 70 jours (45 jours après la pose de l'implant) et est associée à une diminution des niveaux de prolactine périphériques (Sempere et al 1995). Il semble que le début de la saison de reproduction ait lieu après que la femelle ait perçu la diminution de la durée du jour. A l'inverse de ce qui peut être observé chez la brebis, la chevrette n'est pas totalement réfractaire aux jours longs (Sempere et al 1995). En effet, l'exposition à des jours longs depuis le solstice d'été n'empêche pas l'ovulation mais retarde son moment d'environ 46 jours (observé par mesure des concentrations de progestérone). Il est probable que le mécanisme d'entrée en saison sexuelle, dépendant de l'entraînement photopériodique, diffère sensiblement chez la chevrette en comparaison de ce qui peut être observé chez la biche élaphe ou la daine.

Le moment de l'ovulation et donc de la conception est nettement plus précoce chez le chevreuil en comparaison des autres espèces de cervidés originaires des zones tempérées. En revanche, l'existence d'un mécanisme de diapause embryonnaire chez le chevreuil a pour conséquence d'allonger la durée de gestation et de rétablir une période de mises bas proche de celle des autres espèces (mai). Chez les mammifères, la diapause embryonnaire se caractérise par un état de quiescence au stade blastocyste. La chevrette est la seule femelle chez les artiodactyles pour laquelle une implantation différée a pu être mise en évidence. Toutefois, chez la femelle père David, il est possible que des mécanismes d'implantation ou de développement différés existent car la durée de gestation de cette espèce est particulièrement longue (283 jours) en comparaison des autres cervidés (Brinklow et Loudon 1993).

Après fécondation, le développement embryonnaire cesse au stade blastocyste éclos une fois l'environnement utérin atteint. Il semble que le blastocyste n'ait aucune forme d'attachement avec la muqueuse utérine (Aitken 1974). Le blastocyste sphérique vit donc librement dans la lumière utérine durant une période d'environ 5 mois avant de reprendre son développement (élongation) puis de s'implanter. Durant la vie libre de l'embryon, le blastocyste est dans un état de quiescence durant lequel un taux faible de divisions cellulaires peut être observé, permettant une expansion très progressive. L'index mitotique est très faible sur les échantillons prélevés en décembre et semble augmenter progressivement jusqu'à la réactivation $(0,14$ à $1,67 \%$ de cellules en divisions) (Aitken 1981). Lors de la réalisation de marquages de la réplication de l'ADN par incorporation de BrdU (Bromo deoxy Uridine) après incubation in vitro, une nette augmenta- 
tion du pourcentage de cellules marquées peut être observée sur des embryons collectés d'octobre à janvier (Lengwinat et Meyer 1996). Ce marquage ne semble concerner que le trophectoderme.

Les mécanismes de sortie de diapause chez le chevreuil sont peu connus. La coïncidence de la reprise du développement embryonnaire au moment où les jours commencent à s'allonger laissait supposer que la photopériode pouvait provoquer la réactivation. Cependant, la date de mise bas d'une femelle gestante soumise à un régime photopériodique modifié ne semble pas être modifiée (Lincoln et Guinness 1972). Le corps jaune reste pleinement actif et sécrète de la progestérone durant la diapause. Les sécrétions semblent augmenter au moment de l'élongation (Aitken 1974, Sempéré 1977). Il est à noter que chez les femelles non gestantes, le corps jaune reste également actif signe que son maintien semble indépendant d'un signal embryonnaire (Lambert et al 2001). Si l'administration de PGF2 $\alpha$ exogène provoque la lutéolyse (Sempéré et al 1992), l'effet de l'ocytocine sur les sécrétions utérines de PGF2 $\alpha$ n'a pu être démontré chez le chevreuil (Flint et al 1994). De même il semble que les sécrétions d'interféron par le trophoblaste soient inexistantes, et ce, quelque soit le stade du développement de l'embryon (Flint et al 1994). Chez les femelles gestantes, l'augmentation de progestérone semble en fait résulter de l'implantation embryonnaire plutôt que d'en être la cause, et l'origine lutéale ou placentaire des sécrétions responsables de cette augmentation n'a pu être déterminée. Néanmoins, l'augmentation des niveaux de progestérone périphérique décrite par Sempéré ou Aitken n'a pu être confirmée dans l'étude de Lambert et collaborateurs (2001). Les niveaux d'oestradiol ou de prolactine semblent demeurer constants durant la diapause et n'augmentent fortement qu'après l'élongation ou l'implantation (respectivement). Les niveaux d'œstradiol plasmatiques durant l'élongation sont près de 30 fois supérieurs à ceux observés durant la diapause (Lambert et al 2001). De même, les niveaux de PAG (Pregnancy-Associated Glycoproteins) ne sont décelables (avec des anticorps dirigés contre les PAG ovines) qu'après l'implantation. Il est possible que d'autres facteurs secrétés par l'endomètre assurent la réactivation embryonnaire mais de récentes données suggèrent en fait un rôle propre de l'embryon. La synthèse de novo de protéines radio- marquées (incorporation de leucine tritiée) est augmentée dans l'embryon en sortie de diapause et plus tard dans l'endomètre, au stade d'élongation (Lambert et al 2001). Il est donc possible que la réactivation de l'embryon précède et déclenche celle de l'endomètre. Quoiqu'il en soit les mécanismes d'entrée/sortie de diapause restent à déterminer chez le chevreuil et leur compréhension constitue un véritable enjeu en vue d'améliorer la conservation d'embryons chez les ongulés.

\section{2 / Maîtrise de la fonction de reproduction chez les cervidés}

\section{1 / Aspect mâle : collecte et caractéristiques de la semence}

\section{a) Semence éjaculée}

Peu de travaux ont été effectués sur la semence éjaculée du fait du caractère sauvage des cervidés et de l'agressivité des mâles durant la période sexuelle. La collecte au vagin artificiel est cependant envisageable avec des mâles imprégnés, sélectionnés et entraînés (Krzywinski 1976, Gizejewski 2004). Les premiers travaux ont été réalisés chez le renne, espèce dont la domestication est plus aisée (Dott et Utsi 1971). Chez l'élaphe, Krzywinski a démontré qu'il était possible de collecter de la semence de qualité avec une telle approche. Le volume des éjaculats varie de 1,5 à $3 \mathrm{ml}$ avec une motilité progressive des spermatozoïdes de 4060 \% (Krzywinski 1976). De même, la concentration en spermatozoïdes est hautement variable entre individus et entre répétitions $\left(0,07\right.$ à $3,8 \times 10^{9}$ spermatozoïdes / ml). D'après les récents travaux de Gizejewski et collaborateurs (séparation de fractions de l'éjaculat), il semble que cette grande variabilité soit imputable aux sécrétions des glandes annexes (Gizejewski et al 2003). Le volume total des sécrétions des glandes annexes, de l'éjaculat et sa concentration en spermatozoïdes varient significativement selon l'individu et la période collecte (Gizejewski 2004). L'agressivité des mâles lors de la période du rut envers les manipulateurs est une cause d'échec. Pour collecter la semence des mâles refusant le vagin artificiel, il est possible d'utiliser des femelles en oestrus (qui peut être obtenu par synchronisation ou stimulation par l'oestradiol) et équipées de « vagins artificiels internes " . Cette technique est assez complexe à mettre en œuvre du fait des manipulations répétées des animaux qu'elle nécessite (Jabbour et Asher 1991).

\section{b) Semence électro-éjaculée}

En raison de la somme de travail nécessaire à la collecte de semence éjaculée et de la nécessité de disposer d'animaux imprégnés ou apprivoisés, l'électro-éjaculation peut représenter une technique alternative chez les cervidés sauvages (Bierschwal et al 1970, Jaczewski et Jasiorowski 1974). Il convient d'anesthésier les mâles afin d'éviter les souffrances, les risques d'accident et le stress pendant l'intervention, bien que l'utilisation d'anesthésiques représente elle-même un risque pour l'animal et qu'elle puisse éventuellement interférer avec le protocole d'électro-éjaculation. Il semble que les mélanges de kétamine-xylazine ou encore de zoletil@-xylazine soient les plus adaptés (Janovsky et al 2000). Pour notre part, nous avons retenu le mélange de zoletil ${ }^{\circledR}(1 \mathrm{mg} / \mathrm{kg}$, tiletamine-zolazepam 1 : 1) et de xylazine $(1,5 \mathrm{mg} / \mathrm{kg})$. L'effet de la xylazine peut être bloqué rapidement par l'administration intramusculaire de tolazoline $(3 \mathrm{mg} / \mathrm{kg})$ afin de faciliter le réveil de l'individu. Le protocole d'électro éjaculation (voltage, intervalles et nombre de stimulations) semble important pour l'obtention d'une semence de bonne qualité (Cameron 1977). De plus, et à l'instar des observations faites chez les hippotraginés, les sondes doivent être adaptées aux caractéristiques anatomiques des différentes espèces (Cassinello et al 1998). S'il est traditionnellement admis que l'électroéjaculation sur-stimule les glandes annexes et entraîne de ce fait des modifications de la composition de l'éjaculat, pouvant être néfastes pour la survie des spermatozoïdes, les premières observations faites sur la semence électroéjaculée de cervidés (cerf de Virginie) montrent des caractéristiques similaires à la semence ovine avec un volume moyen de 0,5 à $1,5 \mathrm{ml}$ pour un nombre total de spermatozoïdes allant jusqu'à 4,7 milliards/éjaculat (Bierschwal et al 1970). Selon nos propres observations chez le cerf sika, il existe une grande variabilité entre les mâles et d'une séance à une autre pour le même individu. Par ailleurs, il n'est pas rare de voir les échantillons souillés par de l'urine. En saison sexuelle, le volume de l'éjaculat et sa concentration en spermatozoïdes varient respectivement entre 0,5 et $1,1 \mathrm{ml}$ et 0,5 à $5 \times 10^{9}$ spermatozoï$\mathrm{des} / \mathrm{ml}$ (tableau 3). En dépit de la grande variabilité de la qualité de la semence obtenue, cette technique permet de 
Tableau 3. Caractéristiques de la semence éléctro-éjaculée en saison sexuelle lors de collectes successives de trois mâles de cerf sika du Japon (Cervus nippon nippon).

\begin{tabular}{|c|c|c|c|c|c|}
\hline $\mathrm{N}^{\circ}$ animal & Date de collecte & $\begin{array}{c}\text { Volume } \\
\text { de l'éjaculat }(\mathrm{ml})\end{array}$ & Couleur & $\begin{array}{l}\text { Concentration } \\
\left.\text { (x } 10^{6} \mathrm{sptz} / \mathrm{ml}\right)\end{array}$ & $\begin{array}{c}\text { Spermatozoïdes } \\
\text { motiles (\%) }\end{array}$ \\
\hline 2888 & $\begin{array}{l}18 / 10 / 02 \\
21 / 10 / 02 \\
23 / 10 / 02 \\
12 / 11 / 02 \\
14 / 11 / 02\end{array}$ & $\begin{array}{l}0,8 \\
0,8 \\
0,4 \\
0,4 \\
0,5\end{array}$ & $\begin{array}{c}\text { Blanc crême } \\
\text { Blanc crême } \\
\text { Blanc crême } \\
\text { Jaunâtre (Souillé) } \\
\text { Blanc crême }\end{array}$ & $\begin{array}{c}470 \\
2500 \\
1200 \\
470 \\
1900\end{array}$ & $\begin{array}{l}40 \\
60 \\
60 \\
40 \\
40\end{array}$ \\
\hline 4197 & $\begin{array}{l}18 / 10 / 02 \\
21 / 10 / 02 \\
23 / 10 / 02 \\
12 / 11 / 02 \\
14 / 11 / 02\end{array}$ & $\begin{array}{c}1 \\
\text { Echec } \\
0,7 \\
0,35 \\
1,1\end{array}$ & $\begin{array}{c}\text { Blanc crême } \\
- \\
\text { Blanc crême } \\
\text { Jaunâtre (Souillé) } \\
\text { Jaunâtre (Souillé) }\end{array}$ & $\begin{array}{c}640 \\
- \\
625 \\
750 \\
1400\end{array}$ & $\begin{array}{c}40 \\
- \\
80 \\
50 \\
50\end{array}$ \\
\hline 4284 & $\begin{array}{l}18 / 10 / 02 \\
21 / 10 / 02 \\
23 / 10 / 02 \\
12 / 11 / 02 \\
14 / 11 / 02\end{array}$ & $\begin{array}{c}0,5 \\
0,8 \\
0,6 \\
\text { Echec } \\
\text { Echec }\end{array}$ & $\begin{array}{l}\text { Blanc crême } \\
\text { Blanc crême } \\
\text { Blanc crême } \\
\text { - } \\
\text { - }\end{array}$ & $\begin{array}{c}840 \\
540 \\
5400 \\
- \\
-\end{array}$ & $\begin{array}{c}40 \\
60 \\
70 \\
- \\
-\end{array}$ \\
\hline
\end{tabular}

procéder à la congélation d'une proportion importante des éjaculats. Les semences du cerf élaphe, du cerf d'Eld (Cervus eldi thamin) ou du daim présentent des caractéristiques similaires : volume de 1 à $2 \mathrm{ml}$, concentration de 2 à 5 × $10^{9}$ sptz/ml, jusqu'à $80 \%$ de spermatozoïdes motiles (élaphe : Asher et al 1987, Asher et al 1988, cerf d'Eld : Monfort et al 1993a, Monfort et al 1993b, Harnal et al 2001, Asher et al 1993, Asher et al 1996, Asher et al 2000). La technique d'électro-éjaculation semble particulièrement efficace chez le daim puisque le taux de succès de collecte de semence est proche de $100 \%$ (Gosch et Fischer 1989, Asher et al 1993, Asher et al 1996).

\section{c) Semence épididymaire}

La semence est obtenue par cannulation du canal déférent et rétroperfusion de la région caudale de l'épididyme. La technique a été employée postmortem sur des animaux de chasse ou dans un but conservatoire par exemple lorsqu'un individu de haut intérêt génétique vient à mourir. Le sperme épididymaire présente une forte concentration en spermatozoïdes dont le pouvoir fécondant est comparable à celui du sperme éjaculé. Le fluide épididymaire assure une fonction de protection/préservation de la motilité et du pouvoir fécondant des spermatozoïdes qui rend cette semence particulièrement intéressante en vue de la cryopréservation.

En saison sexuelle, cette technique appliquée à l'élaphe sur des animaux de chasse (octobre à novembre) entre 2 et
$24 \mathrm{~h}$ post-mortem nous a permis de collecter des échantillons de semence contenant $7,9 \times 10^{9} \pm 0.68 \times 10^{9}$ spermatozoïdes/ml dont $61,1 \pm 11 \%$ sont motiles $(n=9)$ (Locatelli, non publié). Ces données confirment les observations faites par Krzywinski (1981). Concernant la motilité, une grande variabilité entre individus matures est observée et il semble que ce soit la semence des individus de plus de trois ans qui présente la plus importante proportion de spermatozoïdes motiles (Garde et al 1998, Zomborszky et al 1999). Cette semence peut être conservée plusieurs heures à $4^{\circ} \mathrm{C}$ comme à température ambiante dans l'épididyme ou après perfusion sans trop nuire à sa qualité (élaphe : Garde et al 1998, Guérin et al 2003, sika : Hishinuma et al 2003). Il est donc possible, post mortem, de procéder à la cryopréservation des gamètes. Ainsi, un mâle de haut intérêt génétique peut avoir des descendants, longtemps après sa mort en recourant à l'IA ou à la FIV (Blash et al 2000, Guérin et al 2003). Cette technique est désormais utilisée dans un but conservatoire à la réserve animalière de la Haute Touche dès qu'un animal précieux vient à mourir (par exemple Cerf d'Eld, Muntjac...). La semence épididymaire collectée post-mortem et utilisée en FIV s'est révélée comparable à la semence électro-éjaculée en terme de fécondance (Comizzoli et al 2001, Soler et al 2003). Peu de données concernent les autres espèces.

\section{d) Méthode de cryoconservation}

La cryoconservation de semence, si elle est effectuée lors de la saison sexuelle, permet de disposer à tout moment de l'année, de gamètes fécondants. Une revue très complète, proposée par Asher, résume les techniques de cryoconservation de la semence développées pour les différentes espèces de cervidés (Asher et al 2000). Ces méthodes dérivent directement de celles mises au point pour la semence de bélier ou de bouc. Les dilueurs les plus fréquemment utilisés sont ceux à base de jaune d'œuf (Tris/citrate/fructose ou lactose/lait/glycérol) avec comme agent cryoprotecteur le glycérol dans une proportion de 4 à $8 \%$. Pour la semence obtenue par électro-éjaculation chez l'élaphe, le taux de survie à la congélation est extrêmement variable d'un individu à l'autre et ce, quelques soient les méthodes, "dilueurs » ou agents cryoprotecteurs employés. La motilité au dégel est comprise entre 30 et $70 \%$ de celle observée avant la congélation (Fennessy et al 1990). Selon nos propres observations, la semence épididymaire collectée chez l'élaphe et cryoconservée selon une méthode ovine modifiée présente des caractéristiques similaires puisque la motilité au dégel représente $50 \%$ de celle observée avant la congélation $(49,4 \pm 17,4 \% ; m \pm$ sem, $n=7)$. En revanche, la semence du daim semble plus résistante aux rigueurs de la congélation puisque le taux de survie atteint ou dépasse souvent les $70 \%$ (Asher et al 1990, Asher et al 2000).

\section{2 / Aspect femelle}

Les programmes de types MOET (Multiple Ovulation and Embryo Transfer) sont un outil de choix dans le 
but d'augmenter la prolificité de femelles de haut intérêt génétique. Le MOET associe les techniques de synchronisation de l'oestrus, de stimulation de la croissance folliculaire, d'insémination artificielle (IA) et de transfert embryonnaire.

\section{a) Détection de l'oestrus}

D'une manière générale, il est très difficile de mener des observations du comportement d'oestrus chez les cervidés. Comme nous l'avons évoqué, chez la biche élaphe, le comportement d'oestrus est essentiellement caractérisé par les réponses de la femelle aux sollicitations du mâle. Bien qu'en début d'oestrus, il soit possible d'observer des écoulements vaginaux de mucus clair, ils ne constituent pas une méthode de détection de ce comportement (Guinness et al 1971). Les méthodes de détection d'oestrus reposent donc essentiellement sur l'utilisation de mâles vasectomisés et équipés de harnais " marqueurs » (élaphe : Guinness et al 1971, daim : Asher 1985). Il est également possible d'utiliser des détecteurs électroniques de pression indiquant la monte des mâles $\left(\right.$ HeatWatch $\left.^{\mathrm{TM}}\right)$. L'efficacité semble très inférieure à celle du harnais marqueur lorsque le mâle utilisé est jeune. En revanche, la méthode électronique s'avère efficace lorsque le mâle utilisé est adulte (Bowers et al 2004). Il semble évident que les méthodes de détection de l'oestrus reposant sur l'activité de monte du mâle soient dépendantes de la saison (libido du mâle), de l'âge et du statut social du mâle. De même, il est possible que ces facteurs puissent influencer en retour la venue en oestrus des femelles. En effet, chez le cerf d'Eld (Cervus eldi thamin), la présence de mâles (avec ou sans contact) semble avancer significativement le moment d'oestrus (détecté par lordose en réponse à la pression) et du pic de $\mathrm{LH}$ (Hosack et al 1999).

\section{b) Synchronisation de l'oestrus et de l'ovulation}

Les méthodes de synchronisation du moment d'oestrus et de l'ovulation sont un pré requis pour conduire avec succès les protocoles de reproduction assistée (collecte d'ovocytes, moment d'insémination artificielle, collecte ou transfert embryonnaire...). Une fois encore, ces méthodes dérivent directement des techniques mises au point pour les mammifères domestiques et reposent sur l'administration de progestagènes exogènes sur une période de 12-14 jours à des niveaux comparables à ce qui peut être observé en milieu de cycle. Ils exercent un effet inhibiteur sur les sécrétions de GnRH et par conséquent sur les sécrétions de gonadotrophines (Karsch et al 1977). Pour administrer ces progestagènes sur une durée de 12-14 jours, plusieurs dispositifs peuvent être utilisés comme les éponges vaginales d'acétate de fluorogestone, les CIDR (Controlled Internal Drug Release) ou encore les implants sous-cutanés. Les traitements progestagènes peuvent être associés à l'administration d'analogues de prostaglandines afin de provoquer la lutéolyse d'un éventuel corps jaune. A la suite du retrait de l'implant, une chute rapide des niveaux de progestagènes peut être observée et, en absence de corps jaune fonctionnel, il s'ensuit une levée d'inhibition et une augmentation des niveaux de gonadotrophines. Le retrait du traitement a pour conséquence la reprise de la croissance folliculaire et l'augmentation de l'oestradiol, qui en retour déclenche le pic pré ovulatoire de LH. Si l'administration d'une forte dose de benzoate d'oestradiol suffit à déclencher le comportement d'oestrus chez la brebis ovariectomisée (Robinson 1954, Moore et Robinson 1957), l'exposition préalable à la progestérone permet de diminuer le seuil de sensibilité à l'oestradiol (Karsch et al 1980). Cette exposition à la progestérone est essentielle à l'expression du pic préovulatoire de $\mathrm{GnRH}$ en réponse à l'oestradiol sans pour autant modifier le pic de LH (Caraty et Skinner 1999). Il est à noter que chez la daine ovariectomisée, la présence préalable de progestérone ( 6 ou 12 jours) est indispensable à l'expression de l'oestrus en réponse à l'oestradiol (Jabbour et al 1992). Un effet saisonnier a pu être observé sur l'incidence de l'oestrus en réponse à l'oestradiol, puisqu'en plein anoestrus, la plupart des femelles deviennent réfractaires au traitement, que ce soit chez l'élaphe ou la daine (Jabbour et al 1992, Meikle et Fisher 1990).

Chez la daine, l'utilisation de CIDR pour une durée de 13 jours permet de synchroniser l'oestrus chez 80-90\% des femelles environ $34 \mathrm{~h}$ (sem 2,5 h) après le retrait de l'implant (Asher et al 1990, Jabbour et al 1993). L'intervalle entre l'oestrus et le début du pic de LH est très faible et l'ovulation a lieu dans les 36 heures qui suivent l'oestrus. Chez l'élaphe, l'oestrus survient environ $44 \mathrm{~h}$ après le retrait du CIDR et précède le pic de LH d'une à deux heures et l'ovulation d'environ $24 \mathrm{~h}$ (Asher et al 1992). Cependant, de nombreux fac- teurs peuvent nuire à l'efficacité de ces traitements tels que la période de la saison sexuelle ou le stress associé aux manipulations (Asher et al 1993). L'administration de faibles doses d'eCG (equine Chorionic Gonadotrophin) peu de temps avant ou au moment du retrait du traitement progestagène a été proposée pour réduire ce risque d'échec. En effet, il a été montré que l'administration d'eCG permet d'augmenter le nombre de follicules oestrogéniques ainsi que les niveaux d'oestradiol dans le fluide folliculaire (McLeod et al 2001b). Chez la biche élaphe, l'administration de 200-250 UI d'eCG augmente l'efficacité du traitement (taux de femelles exprimant oestrus et ovulation) et avance le moment de l'oestrus (tableau 4). En revanche, la variance du moment d'oestrus ou d'ovulation n'est pas diminuée et la fréquence des ovulations multiples semblent augmentées (Asher et al 1992). De même, l'eCG ne semble pas permettre de s'affranchir des effets de la composante saisonnière. En effet, en milieu de période d'anoestrus, si son utilisation permet l'expression du comportement d'oestrus associé à un pic de LH, l'ovulation n'est pas systématique (McLeod et al 2001b). Si l'eCG est administrée en routine chez la biche élaphe pour les programmes d'insémination Néo Zélandais notamment pour avancer d'une quinzaine de jours le premier oestrus saisonnier, son utilisation est déconseillée chez la daine. En effet, en comparaison de l'élaphe, il semble que la daine présente une sensibilité augmentée à cette gonadotrophine, entraînant une réponse ovarienne inadaptée dans deux nombreux cas (ovulations multiples ou follicules anovulatoires). Si la réduction de la dose administrée au retrait du traitement progestagène $(50 \mathrm{UI})$ permet de réduire la variance du moment d'oestrus, elle est, contre toute attente, associée à une diminution de fertilité après IA (Jabbour et al 1993).

\section{c) Ovulations multiples}

Les traitements de stimulation reposent essentiellement sur l'administration en fin de traitement progestagène, de gonadotrophines exogènes telles que l'eCG ou la FSH ovine seules ou en association. Ces traitements avancent significativement le moment d'oestrus et d'ovulation (tableau 4). Une forte dose d'eCG (1000-1200 UI) peut être utilisée à des fins superovulatoires chez de nombreuses espèces de cervidés. Cependant, dans au moins $10 \%$ des cas (chez l'élaphe), cette hormone semble provoquer une régression lutéale pré- 
Tableau 4. Effets de différents traitements de stimulation sur les moments moyens d'oestrus, du pic de LH et d'ovulation chez la biche élaphe exprimés par rapport au retrait du CIDR $(h \pm$ sem).

\begin{tabular}{|l|c|c|c|c|c|c|l|}
\hline Traitements & $\mathrm{N}$ & $\begin{array}{c}\text { Femelles exprimant } \\
\text { oestrus et ovulation }\end{array}$ & $\begin{array}{c}\text { Corps } \\
\text { jaunes }\end{array}$ & Oestrus & Pic de $\mathrm{LH}^{*}$ & Ovulation & Références \\
\hline CIDR & $\begin{array}{c}12 \\
7\end{array}$ & $\begin{array}{c}7 / 12 \\
6 / 7\end{array}$ & $\begin{array}{c}0,6 \pm 0,1 \\
1 \pm 0,2\end{array}$ & $\begin{array}{c}44,6 \pm 1 \\
43,6 \pm 2,6\end{array}$ & $\begin{array}{c}45,1 \pm 1,3 \\
\mathrm{ND}\end{array}$ & $\begin{array}{c}69,3 \pm 1,2 \\
71,3 \pm 5,8\end{array}$ & $\begin{array}{l}\text { Asher et al 1992 } \\
\text { Jabbour et al 1994 }\end{array}$ \\
\hline $\begin{array}{l}\text { CIDR } \\
\text { eCG 200 UI }\end{array}$ & 8 & $7 / 8$ & $1 \pm 0,2$ & $37,4 \pm 2$ & $38,3 \pm 2,3$ & $58 \pm 2,4$ & Asher et al 1992 \\
\hline $\begin{array}{l}\text { CIDR } \\
\text { eCG 1200 UI }\end{array}$ & 7 & $6 / 7$ & $8,4 \pm 2,7$ & $16,6 \pm 2,7$ & $\mathrm{ND}$ & $31 \pm 5,7$ & Jabbour et al 1994 \\
\hline $\begin{array}{l}\text { CIDR } \\
\text { eCG 200 UI } \\
\text { FSH 0.5 UI }\end{array}$ & 8 & $8 / 8$ & $8,3 \pm 1,5$ & $16,3 \pm 1,7$ & $14 \pm 0,9$ & $36,3 \pm 3,1$ & Asher et al 1992 \\
\hline
\end{tabular}

maturée des corps jaunes (Jabbour et al 1994). Il est probable que ce phénomène soit associé à l'augmentation des niveaux d'oestradiol, qui potentialise la sécrétion de prostaglandines induite par l'ocytocine et provoque la lutéolyse (Bainbridge et al 1998, Bainbridge et al 1996, Bainbridge et al 1996). De même, il n'est pas rare d'observer des follicules non ovulatoires, kystiques ou lutéinisés (Thompson et Asher 1988). Lors de la réalisation de programmes d'insémination et de collecte d'embryons, il est possible que ce phénomène puisse altérer le transport des gamètes et des embryons et expliquer les faibles niveaux de fécondation et de collecte des embryons généralement observés (Argo et al 1994, Jabbour et al 1994, Asher et al 1995). Les traitements utilisant la FSH ovine très purifiée (peu d'activité LH) ont également été développés chez les cervidés (Fennessy et al 1994). Compte tenu de la très courte demi-vie de cette hormone, il convient d'effectuer plusieurs administrations en fin de traitement progestagène. Chez l'élaphe, les injections intramusculaires sont généralement effectuée toutes les 12 heures et sur une période de 4 jours (Fennessy et al 1989). Afin de réduire les manipulations des femelles, il a été envisagé d'administrer la FSH via des mini pompes osmotiques. D'après les résultats de la seule étude comparative (portant sur peu d'animaux), il semble que la méthode d'administration par injections intra musculaire soit la plus adaptée (Fennessy et al 1989). Pour éviter les réponses de type « tout ou rien », il est fréquent d'administrer une faible dose d'eCG (200 UI) en début de traitement FSH (Asher et al 1995). La dose optimale de FSH ovine chez la daine et l'élaphe est de 0,5 UI, permettant d'obtenir plus de 9 ovulations en moyenne (figure 7). Cependant, après IA et collecte des embryons par laparotomie, les
Figure 7. Réponses ovariennes (nombre de corps jaunes et de follicules anovulatoires) après synchronisation et administration d'eCG (200 UI) et de différentes doses de FSH ovine (0, 0,25, 0,5, 0,75 et $1 \mathrm{UI})$ chez a) la biche élaphe et b) la daine (Asher et al 1995).

a)

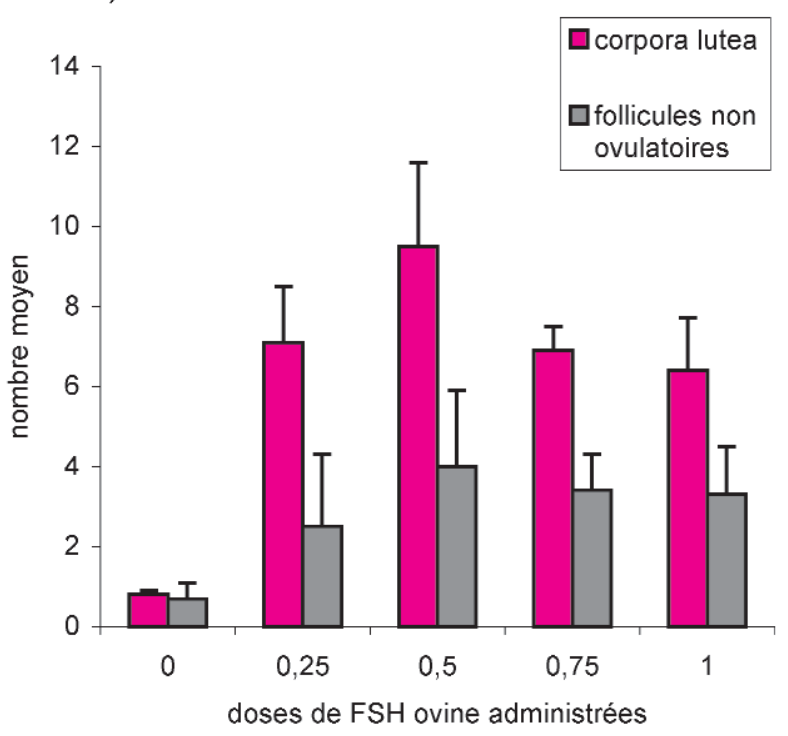

b)

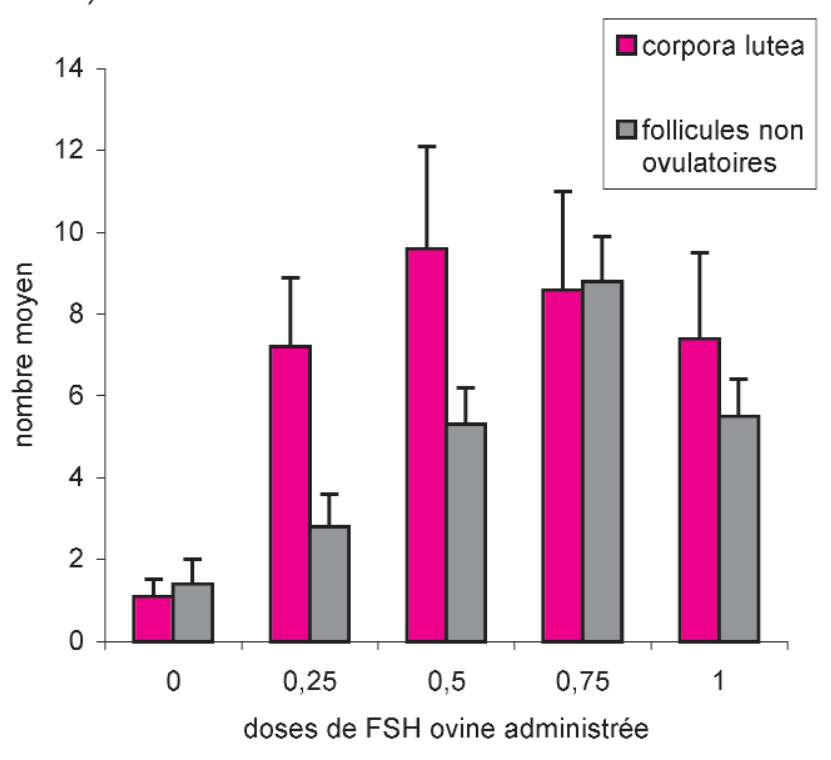


taux de fécondation et de collecte des embryons sont là encore, souvent décevants (Asher et al 1995). De même, la réponse ovarienne peut être très variable selon le génotype, y compris entre sous-espèces proches. La comparaison de la réponse ovulatoire des traitements de stimulation FSH répétés est près de 3 fois inférieure chez l'élaphe (Cervus elaphus scoticus) que chez l'hybride wapiti/élaphe (Asher et al 2000b). Outre le génotype, il est intéressant de noter que la saison sexuelle influence significativement la capacité de réponse ovarienne à la FSH $(0,4$ UI). La réponse ovulatoire au moment du solstice d'été devient nulle chez l'élaphe et les hybrides père David (1/4) et quasi nulle chez les hybrides wapiti (Asher et al 2000b).

\section{3 / Production in vitro (PIV) d'embryons}

Les systèmes de production in vitro (PIV) d'embryons développés pour les cervidés (du genre Cervus uniquement) dérivent directement des systèmes mis au point ces deux dernières décennies chez les bovins (Berg et al 1995, Comizzoli et al 2001). La technique de PIV permet de s'affranchir de la composante animale et semble de ce fait être une réponse aux difficultés rencontrées avec les techniques de MOET (voir cidessus). Des trois étapes clés de la production in vitro d'embryons, deux semblent aujourd'hui bien maîtrisées, à savoir la maturation des ovocytes et leur fécondation in vitro (MIV et FIV). L'ultime étape est celle du développement embryonnaire in vitro (DIV).

\section{1 / Collecte d'ovocytes et Maturation in vitro (MIV)}

In vivo, l'ovocyte (bloqué au stade de vésicule germinale ou prophase de première division méiotique) va progressivement acquérir sa compétence au développement au cours de la croissance folliculaire et suite à la décharge ovulante. Il subit une maturation cytoplasmique et nucléaire qui se traduisent par de nombreuses évolutions biochimiques et morphologiques incluant notamment la migration des granules corticaux et la reprise de la méiose jusqu'au stade de métaphase de deuxième division méiotique (MII). Chez la vache, il est possible de ponctionner des ovocytes matures dont la compétence au développement est élevée en ponctionnant des follicules préovulatoires 20-24 $\mathrm{h}$ après le pic de LH (Dieleman et al 2002). Cette technique suppose une bonne maîtrise de la synchronisation du pic de LH et, par conséquent, ne semble pas applicable aux cervidés. Chez la biche élaphe $(n=14)$ après synchronisation et stimulation hormonale (1000 UI eCG) et $24 \mathrm{~h}$ après le retrait du traitement progestagène, il a été possible de ponctionner par voie laparoscopique 2,44 follicules préovulatoires par animal ( 95 follicules en 39 sessions) et de collecter 27 complexes cumulus-ovocytes $(0,69$ par animal et par session) non dégénérés (Bainbridge et al 1999). Il semble donc difficile par cette technique de collecter un nombre important d'ovocytes matures de bonne qualité. Par conséquent, il a été envisagé de ponctionner des follicules contenant des ovocytes immatures et de procéder à leur maturation in vitro (MIV). Cette technique ne concerne que les ovocytes issus de follicules de plus de $2 \mathrm{~mm}$ de diamètre puisqu'ils semblent seuls capables d'accomplir leur méiose in vitro. Chez la biche élaphe, le recrutement folliculaire concerne les follicules de 2 à $3 \mathrm{~mm}$ de diamètre et il est possible en saison sexuelle, suite à une stimulation hormonale (FSH ovine 0,4 ui) d'observer près de 10 follicules de plus de $3 \mathrm{~mm}$ par animal au moment du retrait du CIDR (Asher et al 1997). La ponction de follicules chez des animaux non stimulés peut également être envisagée offrant ainsi la possibilité de travailler à partir d'ovaires obtenus après abattage d'animaux de chasse ou d'élevage. En saison sexuelle, il est possible de collecter chez l'élaphe (ovaires d'abattoir) une moyenne de 3,4 ovocytes de bonne qualité (plus de trois rangées de cellules de cumulus et cytoplasme homogène) par ovaire tandis que chez la biche sika, la pratique de l'ovum pick-up par voie laparoscopique permet de collecter 1,5 ovocytes de bonne qualité par biche et par session (Comizzoli et al 2001).

L'intégrité des complexes cumulusovocytes lors de la MIV apparaît indispensable à l'acquisition d'une compétence au développement élevée. Chez la vache, lorsque l'on mature in vitro des ovocytes triés selon l'intégrité de leur cumulus, les taux de clivage et de développement ultérieurs sont affectés par le tri (Khurana et Niemann 2000). In vitro, il est probable que les couches cellulaires du cumulus outre leur fonction de protection contre le stress oxydatif, assurent le transport de métabolites et le relais de signaux extérieurs, tels que le signal ovulatoire de LH, jusqu'à l'ovocyte (Park et al 2004). Les cellules du cumulus oopho- rus sont en contact étroit avec l'ovocyte via des prolongements cellulaires au travers de la zone pellucide et l'établissement de jonctions communicantes. Ces jonctions autorisent les échanges métaboliques et permettent au cumulus de jouer un rôle complexe dans le blocage/reprise de la maturation nucléaire (Luciano et al 2004). Il est donc important de préserver la viabilité des ces cellules et leur lien avec l'ovocyte lors de la ponction.

Les milieux de MIV les plus fréquemment utilisés chez les mammifères domestiques se composent d'un milieu de culture (TCM-199) supplémenté en gonadotrophines (FSH et LH), en oestradiol et en sérum de veau fœtal $(10 \%)$, selon les espèces et les auteurs. Chez les ovins et caprins, en plus de la FSH, le fluide folliculaire (collecté en ponctionnant des follicules de grande taille, non atrétiques) peut être ajouté comme source d'oestrogènes, de facteurs de croissance ou d'antioxydants et la stimulation hormonale préalable au prélèvement du fluide folliculaire par la eCG renforce la compétence au développement des ovocytes ainsi maturés (Cognie et al 1995, Guler et al 2000). L'utilisation de l'EGF (Epidermal Growth Factor) est également courante chez les petits ruminants. Chez la biche, les travaux concernant la maturation in vitro de l'ovocyte se sont jusqu'à présent limités à l'observation de la maturation nucléaire. Elle peut être estimée soit par l'émission du globule polaire soit par fixation et coloration de l'ovocyte afin de visualiser l'état de son noyau (orcéine, Hoeschst 33342). Chez les biches sika et élaphe, Comizzoli et collaborateurs ont observé que le pourcentage d'ovocytes au stade MII après $24 \mathrm{~h}$ de MIV dans le milieu TCM-199 enrichi en FSH ovine $(50 \mathrm{ng} / \mathrm{ml})$ et en fluide folliculaire $(10 \%)$ atteint respectivement 76 et $78 \%$. De même, $75 \%$ des ovocytes atteignent le stade MII après 27 heures dans le milieu TCM-199 supplémenté en FSH, LH, oestradiol $17 \beta$ et en sérum de veau fotal (SVF) (Berg et al 2002b). Alors que l'EGF est couramment utilisé avec succès chez les mammifères domestiques, son utilisation chez les cervidés $(10 \mathrm{ng} / \mathrm{ml})$ réduit dramatiquement le taux de maturation nucléaire à $24 \mathrm{~h}$ puisqu'il n'atteint que $14 \%$ chez le sika et $25 \%$ chez l'élaphe (Comizzoli et al 2001).

Ces différences de réactivité entre ovocytes de différentes espèces soulignent la nécessité d'une meilleure compréhension des mécanismes généraux 
de contrôle du cycle cellulaire de l'ovocyte et l'adaptation des techniques à chaque nouvelle espèce prise en compte dans les programmes de sauvegarde.

\section{2 / Fécondation in vitro (FIV)}

La fécondation in vitro (FIV) consiste à effectuer une co-incubation des gamètes mâles et femelles matures. In vivo, au travers de la migration dans le tractus génital femelle le spermatozoïde va progressivement acquérir son pouvoir fécondant (Bavister 2002). Ce phénomène appelé capacitation doit être reproduit in vitro pour permettre la pénétration du spermatozoïde dans l'ovocyte. Lors de fécondations in vitro, l'étape dite de capacitation est généralement réalisée en amont de la co-incubation des gamètes. De nomreux agents dits capacitants (comme le sérum notamment) ajoutés à des milieux de culture propices à la fois à la survie des spermatozoïdes et des ovocytes peuvent être utilisés.

Berg et collaborateurs ont dans un premier temps montré qu'il était possible de féconder des ovocytes avec de la semence congelée capacitée dans un milieu de type SOF (Synthetic Oviduct Fluid) supplémenté de sérum de brebis en en chaleur (Sheep Serum, SS) à hauteur de $20 \%$ (v:v). Les embryons obtenus se sont révélés viables puisque après transfert dans l'oviducte de receveuses synchronisées, 5 des 15 biches transférées étaient gestantes (Berg et al 1995). La fécondation dans le milieu TALP (Tyrode Albumine Lactate Pyruvate) utilisé classiquement en FIV bovine est également envisageable chez les cervidés. Cependant, la motilité du sperme de cerf élaphe dégelé (lavé par centrifugation) dans le milieu TALP décroît fortement au cours du temps puisqu'elle n'est plus que de $10 \%$ au bout de $4 \mathrm{~h}$ d'incubation et nulle au bout de $8 \mathrm{~h}$ (Berg et al 2002c). Il est intéressant de noter que cette semence, après capacitation en présence d'héparine, s'est révélée peu fécondante dans le milieu TALP (7,2 \% d'ovocytes fécondés). Dans l'étude menée par Comizzoli et collaborateurs (2001), une chute moins drastique de la motilité a pu être observée avec de la semence de cerf élaphe ou sika préalablement sélectionnée sur gradient de Percoll et incubée dans le TALP avec ou sans sérum de brebis. Les niveaux de fécondation avec ces semences utilisées en FIV (milieu TALP + SS) se sont révélés relativement importants (45-50\%). Les niveaux de fécondation dans le milieu SOF en présence de BSA et d'héparine se sont révélés décevants en comparai- son de l'utilisation du sérum de brebis en chaleur qui permet d'obtenir le taux de fécondation maximum (Berg et al 2002a).

A l'instar de ce qui peut être observé chez les mammifères domestiques, il est probable qu'une importante variabilité de la fécondance in vitro puisse exister entre les mâles, voire entre éjaculats d'un même mâle. Nos propres observations, réalisées sur 6 échantillons de semence épididymaire de cerf élaphe montrent que les niveaux de fécondations obtenus en FIV hétérologue (ovocytes caprins) varient de 5 à $60 \%$ entre individus (Locatelli, non publié). Aussi, il est souvent préférable d'utiliser les semences de plusieurs mâles dans un même puits de fécondation lorsque la filiation des futurs produits n'est pas déterminante.

\section{3 / Développement in vitro (DIV)}

Chez les mammifères domestiques, le milieu de DIV le plus utilisé est le milieu de type SOF supplémenté en acides aminés et en sérum de veau fœtal. La composition minérale de ce milieu se veut la plus proche possible de ce qui peut être observé in vivo dans l'environnement tubaire bovin. Placés en culture pendant 7 à 8 jours dans ce milieu supplémenté de sérum, 30 à $50 \%$ des embryons bovins, caprins ou ovins produits in vitro atteignent le stade blastocyste. Les premières données concernant l'embryon de cerf élaphe portent sur l'embryon produit in vivo au stade 1-2 cellules et cultivé dans différents systèmes de culture : culture dans l'oviducte ligaturé de brebis ; co-culture de cellules épithéliales dans le TCM 199 supplémenté en sérum de biche ; milieu SOF supplémenté en sérum humain.

Les taux de développement au stade blastocyste se sont révélés relativement faibles pour des embryons produits in vivo (22-26\% des œufs collectés) mais identiques dans les 3 systèmes de culture suggérant que le milieu SOF pouvait être utilisé pour la culture d'embryons de cervidés (Berg et al 1995, Berg et al 1995). Les études ultérieures menées sur l'embryon de cerf produit in vitro se sont jusqu'à présent conclues par un taux de développement inférieur à $10 \%$. La plupart des embryons restent bloqués au stade 8 cellules que ce soit chez l'élaphe (Fukui et al 1991, Bainbridge et al 1999, Berg et al 2002a) ou chez le sika, espèce pour laquelle la blastulation après produc- tion in vitro n'a jamais été observée (Comizzoli et al 2001). Selon 1'hypothèse émise par Berg et collaborateurs, l'embryon de cerf doit présenter des besoins spécifiques en comparaison de ce qui peut être observé chez les mammifères domestiques et ces besoins spécifiques pourraient être plus déterminants lorsqu'il est produit in vitro.

En se basant sur la composition du fluide de l'oviducte de biches élaphe, Berg et collaborateurs ont développé un milieu de type SOF optimisé pour répondre aux besoins spécifiques des embryons de cervidés et dénommé DSOF (Deer-Synthetic Oviduct Fluid). Les principales modifications apportées concernent les concentrations de calcium (augmentée), de phosphates inorganiques et de glucose (diminuées) et ont conduit à l'élaboration d'un milieu biphasique comprenant une étape de culture précoce et une étape tardive. L'utilisation de ces milieux en FIV puis en culture permet d'augmenter significativement le taux de clivage et la compétence au développement des embryons produits (Berg et Asher 2003). Il est à noter que le sérum de veau fœtal n'est pas ajouté durant la culture. Cependant, les niveaux de développement obtenus dans ces conditions à partir d'ovocytes d'élaphe collectés sur ovaires d'abattoirs restent dramatiquement faibles $(12 \%$ des clivés). Des résultats similaires ont pu être observés à partir d'ovocytes collectés par OPU (voie transvaginale) avec ou sans stimulation hormonale préalable (GnRH ou FSH) chez l'élaphe ou le wapiti (Berg et Asher 2003). De plus, il semble que la compétence au développement des ovocytes collectés soit sous la dépendance d'un fort effet saisonnier puisque avec l'avancée de la saison de reproduction, le taux de développement chute dramatiquement et finit par devenir nul.

Les travaux de recherche menés au laboratoire à partir d'ovocytes collectés chez l'élaphe et le cerf sika du Japon ont permis de montrer que l'utilisation d'un tapis de cellules d'oviducte ovin dans le milieu SOF permettait la blastulation d'une forte proportion d'embryons. Pour ces deux espèces près de $30-40 \%$ des embryons produits in vitro et placés en co-culture atteignent le stade blastocyste 8 jours après fécondation. Il semble donc que, placés dans des conditions appropriées, les embryons de cerf produits in vitro soient capables de se développer. La compréhension de l'effet bénéfique de la présence de cellules tubaires devrait per- 
mettre de définir de nouveaux milieux de culture adaptés aux besoins spécifiques de l'embryon de cerf.

\section{Conclusion}

Les connaissances de la fonction de reproduction des cervidés se sont considérablement améliorées au cours des dernières années et plus particulièrement chez le daim et le cerf élaphe. Bien que semblable en de nombreux points à celle des ruminants domestiques, la physiologie de la reproduction des cervidés montre de nombreuses particularités. Les variations saisonnières d'activité chez les espèces originaires de zones tempérées sont nette- ment plus marquées que chez les espèces domestiques et apparaissent plus difficilement maîtrisables. Les études menées au travers de la diversité de la famille des cervidés, montrent que de nombreuses exceptions sont observées, traduisant une étonnante capacité d'adaptation de ces ruminants à l'environnement. De nombreuses questions fondamentales restent à élucider (différences de sensibilité à la photopériode entre les espèces, mécanismes de régulation de la pousse des bois chez le mâle, contrôle de la diapause chez le chevreuil...).

Dans un premier temps, l'utilisation des biotechnologies de la reproduction a été proposée en vue d'améliorer l'efficacité de la sélection des programmes d'élevage. Les techniques de synchronisation d'oestrus et d'insémination artificielle sont notamment utilisées dans ce but en Nouvelle Zélande et des sociétés privées commercialisent les semences de mâles sélectionnés. Elles ne semblent cependant applicables que dans les élevages ou le degré de domestication des animaux est élevé. Aujourd'hui, l'intérêt de ces recherches est renforcé par l'utilisation possible de ces techniques dans la conservation de la biodiversité. Les avancées dans le domaine de la stimulation de la croissance follicullaire, de la production in vitro et de la cryoconservation d'embryons semblent en effet permettre, à terme, de pouvoir envisager des applications aux espèces menacées d'extinction.

\section{Références}

Adam C.L., McDonald I., Moir C.E., Pennie K., 1988. Foetal development in red deer (Cervus elaphus). 1. Growth of the foetus and associated tissues. Anim. Prod., 46, 131138.

Adam C.L., Moir C.E., Atkinson T., 1985. Plasma concentrations of progesterone in female red deer (Cervus elaphus) during the breeding season, pregnancy and anoestrus. J. Reprod Fertil., 74(2), 631-636.

Aitken R.J., 1974. Delayed implantation in roe deer (Capreolus capreolus). J. Reprod. Fertil., 39, 225-233.

Aitken R.J., 1981. Aspects of delayed implantation in the roe deer (Capreolus capreolus). J. Reprod. Fertil., Suppl 29, 83-95.

Anderson G.M., Barrell G.K., 1998a. Effects of thyroidectomy and thyroxine replacement on seasonal reproduction in the red deer hind. J. Reprod. Fertil., 113(2), 239-250.

Anderson G.M., Barrell G.K., 1998b. Effects of thyroidectomy and thyroxine replacement on seasonal reproduction in the red deer hind. J. Reprod. Fertil., 113(2), 239-250. 98b.

Arendt J., 1986. Assay of melatonin and its metabolites: results in normal and unusual environments. J. Neural Transm., Suppl 21, 11-33.

Argo C.M., Jabbour H.N., Goddard P.J., Webb R., Loudon A.S., 1994. Superovulation in red deer (Cervus elaphus) and Pere David's deer (Elaphurus davidianus), and fertilization rates following artificial insemination with Pere David's deer semen. J. Reprod. Fertil., 100, 629636.

Asher G.W., 1985. Oestrous cycle and breeding season of farmed fallow deer, Dama dama. J. Reprod. Fertil., 75, 521-529.

Asher G.W., Barrell G.K., Adam J.L., Staples L.D., 1988. Effects of subcutaneous melatonin implants on reproductive seasonality of farmed fallow deer (Dama dama). J. Reprod. Fertil., 84, 679-691.
Asher G.W., Barrell G.K., Peterson A.J. 1986. Hormonal changes around oestrus of farmed fallow deer, Dama dama. J. Reprod. Fertil., 78, 487-496.

Asher G.W., Berg D.K., Beaumont S., Morrow C.J., O'Neill K.T., Fisher M.W., 1996. Comparison of seasonal changes in reproductive parameters of adult male European fallow deer (Dama dama dama) and hybrid Mesopotamian x European fallow deer $(D . d$. mesopotamica $x D$. d. dama). Anim. Reprod. Sci., 45, 201-215.

Asher G.W., Berg D.K., Evans G., 2000. Storage of semen and artificial insemination in deer. Anim. Reprod. Sci., 62, 195-211.

Asher G.W., Day A.M., Barrell G.K., 1987. Annual cycle of liveweight and reproductive changes of farmed male fallow deer (Dama dama) and the effect of daily oral administration of melatonin in summer on the attainment of seasonal fertility. J. Reprod. Fertil., 79, 353-362.

Asher G.W., Fisher M.W., Berg D.K., Waldrup K.A., Pearse A.J., 1996a. Luteal support of pregnancy in red deer (Cervus elaphus): effect of cloprostenol, ovariectomy and lutectomy on the viability of the post-implantation embryo. Anim. Reprod. Sci., 41(2), 141-151.

Asher G.W., Fisher M.W., Fennessy P.F. 1996b. Environmental constraints on reproductive performance of farmed deer. Anim. Reprod. Sci., 42(1-4), 35-44.

Asher G.W., Fisher M.W., Fennessy P.F., Mackintosh C.G., Jabbour H.N., Morrow C.J. 1993. Oestrous synchronization, semen collection and artificial insemination of farmed red deer (Cervus elaphus) and fallow deer (Dama dama). Anim. Reprod. Sci., 33(1-4), 241-265.

Asher G.W., Fisher M.W., Jabbour H.N., Smith J.F., Mulley R.C., Morrow C.J., Veldhuizen F.A., Langridge M., 1992. Relationship between the onset of oestrus, the preovulatory surge in luteinizing hormone and ovulation following oestrous synchronization and superovulation of farmed red deer (Cervus elaphus). J. Reprod. Fertil., 96, 261-273.
Asher G.W., Fisher M.W., Smith J.F., Jabbour H.N., Morrow C.J., 1990. Temporal relationship between the onset of oestrus, the preovulatory LH surge and ovulation in farmed fallow deer, Dama dama. J. Reprod. Fertil., 89, 761-767.

Asher G.W., Jabbour H.N., Thompson J.G., Tervit H.R., Morrow C.J. 1995. Superovulation of farmed red deer (Cervus elaphus) and fallow deer (Dama dama): Incidence of ovulation and changes in plasma hormone concentrations during the pre-ovulatory period in relation to ova recovery and fertilisation. Anim. Reprod. Sci., $38(1-2), 137-154$

Asher G.W., Kraemer D.C., Magyar S.J., Brunner M., Moerbe R., Giaquinto M. 1990. Intrauterine insemination of farmed fallow deer (Dama dama) with frozen-thawed semen via laparoscopy. Theriogenology, 34(3), 569-577.

Asher G.W., Monfort S.L., Wemmer C., 1999. Comparative reproductive function in cervids: implications for management of farm and zoo populations. J. Reprod. Fertil., Suppl 54, 143156.

Asher G.W., Muir P.D., Semiadi G., O’Neill K.T., Scott I.C., Barry T.N., 1997. Seasonal patterns of luteal cyclicity in young red deer (Cervus elaphus) and sambar deer (Cervus unicolor). Reprod. Fertil. Dev., 9, 587-596.

Asher G.W., O’Neill K.T., Scott I.C., Mockett B.G., Fisher M.W., 2000a. Genetic influences on reproduction of female red deer (Cervus elaphus). I. Seasonal luteal cyclicity. Anim. Reprod. Sci., 59, 43-59.

Asher G.W., O’Neill K.T., Scott I.C., Mockett B.G., Pearse A.J., 2000b. Genetic influences on reproduction of female red deer (Cervus elaphus). II. Seasonal and genetic effects on the superovulatory response to exogenous FSH. Anim. Reprod. Sci., 59, 61-70.

Asher G.W., Peterson A.J., 1991. Pattern of $\mathrm{LH}$ and testosterone secretion of adult male fallow deer (Dama dama) during the transition into the breeding season. J. Reprod. Fertil., 91, 649-654. 
Asher G.W., Peterson A.J., Bass J.J., 1989a. Seasonal pattern of $\mathrm{LH}$ and testosterone secretion in adult male fallow deer, Dama dama. J. Reprod. Fertil., 85, 657-665.

Asher G.W., Peterson A.J., Duganzich D., 1989b. Adrenal and ovarian sources of progesterone secretion in young female fallow deer, Dama dama. J. Reprod. Fertil., 85, 657-665.

Asher G.W., Peterson A.J., Watkins W.B., 1988. Hormonal changes during luteal regression in farmed fallow deer, Dama dama. J. Reprod. Fertil., 84, 379-386.

Asher G.W., Scott I.C., O’Neill K.T., Smith J.F., Inskeep E.K., Townsend E.C., 1997. Ultrasonographic monitoring of antral follicle development in red deer (Cervus elaphus). J. Reprod. Fertil., 111, 91-99.

Audige L., Wilson P.R., Morris R.S., 1999. Reproductive performance of farmed red deer (Cervus elaphus) in New Zealand. I. Descriptive data. Anim. Reprod. Sci., 55, 127-141.

Bainbridge D.R., Catt S.L., Evans G., Jabbour H.N., 1999. Successful in vitro fertilization of in vivo matured oocytes aspirated laparoscopically from red deer hinds (Cervus elaphus). Theriogenology, 51, 891-898.

Bainbridge D.R., Davies M.H., Scaramuzzi R.J., Jabbour H.N., 1996. Exogenous interferon delays luteal regression in red deer hinds (Cervus elaphus) by suppressing steroid-induced endometrial oxytocin sensitivity. Biol. Reprod., $55,883-888$.

Bainbridge D.R., Deakin D., Jabbour H.N., 1998. Premature luteal regression induced by equine chorionic gonadotropin and estrogen is suppressed by administration of exogenous interferon in red deer (Cervus elaphus). Biol. Reprod., 58, 124-129.

Bainbridge D.R., Hunter M.G., Chapple D.G., Flint A.P., Jabbour, H.N., 1996. Role of estrogen and prostaglandin F2 alpha in premature luteal regression in monovulatory and superovulated red deer (Cervus elaphus). Biol. Reprod., 54, 347-354.

Bainbridge D.R., Jabbour H.N., 1997. Effect of pregnancy and exogenous interferon on synchronous pulsatile release of oxytocin and luteolytic prostaglandin F2 alpha in red deer (Cervus elaphus). J. Reprod. Fertil., 111, 299-307.

Bainbridge D.R., Jabbour, H.N., 1999. Source and site of action of anti-luteolytic interferon in red deer (Cervus elaphus): possible involvement of extra-ovarian oxytocin secretion in maternal recognition of pregnancy. J. Reprod. Fertil., 116, 305-313.

Bavister B.D., 2002. Early history of in vitro fertilization. Reproduction, 124, 181-196.

Beckers J.F., Drion P.V., Garbayo J.M., Perenyi Z., Zarrouk A., Sulon J., Remy B., Szenci O., 1999. Pregnancy associated glycoproteins in ruminants: inactive members of the aspartic proteinase family. Acta Vet. Hung., 47, 461-469.

Berg D.K., Asher, G.W., 2003. New developments reproductive technologies in deer. Theriogenology, 59, 189-205.

Berg D. K., Asher G. W., Pugh P. A., Tervit H. R., Thompso, J. G, 1995. Pregnancies following the transfer of in vitro matured and fertilized red deer (Cervus elaphus) oocytes. Theriogenology, 43(1), 166.

Berg D.K., Pugh P.A., Thompson J.G., Asher G.W., 2002a. Development of in vitro embryo production systems for red deer (Cervus elaphus). Part 3. In vitro fertilisation using sheep serum as a capacitating agent and the subsequent birth of calves. Anim. Reprod. Sci., 70, 85-98.

Berg D.K., Thompson J.G., Asher G.W., 2002 b. Development of in vitro embryo production systems for red deer (Cervus elaphus). Part 2 . The timing of in vitro nuclear oocyte maturation. Anim. Reprod. Sci., 70, 77-84.

Berg D.K., Thompson J.G., Asher G.W., 2002c. Development of in vitro embryo production systems for red deer (Cervus elaphus). Part 1. Effect of epithelial oviductal monolayers and heparin on in vitro sperm motility and penetration of in vitro matured oocytes. Anim. Reprod. Sci., 70, 65-76.

Berg D.K., Thompson J.G., Pugh P.A., Tervit H. R., Asher G. W., 1995. Successful in vitro culture of early cleavage stage embryos recovered from superovulated red deer (Cervus elaphus). Theriogenology, 44(2), 247-254.

Bierschwal C.J., Mather E.C., Martin C.E., Murphy D.A., Korschgen, L.J., 1970. Some characteristics of deer semen collected by electroejaculation. J. Am. Vet. Med. Assoc., 157, 627-632.

Blash S., Melican D., Gavin W., 2000. Cryopreservation of epididymal sperm obtained at necropsy from goats. Theriogenology, 54, 899-905.

Bowers S.D., Brown C.G., Strauch T.A., Gandy B.S., Neuendorff D.A., Randel R.D., Willard S.T., 2004. Artificial insemination following observational versus electronic methods of estrus detection in red deer hinds (Cervus elephus). Theriogenology, 62, 652-663.

Brinklow B.R., Loudon A.S., 1993. Gestation periods in the Pere David's deer (Elaphurus davidianus): evidence for embryonic diapause or delayed development. Reprod. Fertil. Dev., 5, 567-575.

Bubenik G.A., Pomerantz D.K., Schams D., Smith, P.S., 1987. The role of androstenedione and testosterone in the reproduction and antler growth of a male white-tailed deer. Acta Endocrinol., 114, 147-152.

Bubenik G.A., Schams D., White R.J., Rowell J., Blake J., Bartos L., 1997. Seasonal levels of reproductive hormones and their relationship to the antler cycle of male and female reindeer (Rangifer tarandus). Comp. Biochem. Physiol. Ser. B Biochem. Mol. Biol., 116, 269-277.

Cameron R.D., 1977. Semen collection and evaluation in the ram. The effect of method of stimulation on response to electroejaculation. Aust. Vet. J., 53, 380-383.

Caraty A., Skinner, D.C., 1999. Progesterone priming is essential for the full expression of the positive feedback effect of estradiol in inducing the preovulatory gonadotropin-releasing hormone surge in the ewe. Endocrinology, 140, 165-170.

Carragher J.F., Ingram J.R., Matthews L.R., 1997. Effects of yarding and handling procedures on stress responses of red deer stags
(Cervus elaphus). Appl. Anim. Behav. Sci., 51 (1-2), 143-158.

Cassinello J., Abaigar T., Gomendio M., Roldan E.R., 1998. Characteristics of the semen of three endangered species of gazelles (Gazella dama mhorr, G. dorcas neglecta and G. cuvieri). J. Reprod. Fertil., 113, 35-45.

Ceballos G., Ehrlich P.R., 2002. Mammal population losses and the extinction crisis. Science, 296, 904-907.

Chapple R.S., English A.W., Mulley R.C., 1993. Characteristics of the oestrous cycle and duration of gestation in chital hinds (Axis axis). J. Reprod. Fertil., 98, 23-26.

Chapman N.G., Harris S., 1991. Evidence that the seasonal antler cycle of adult Reeves' muntjac (Muntiacus reevesi) is not associated with reproductive quiescence. J. Reprod. Fertil., 92, 361-369.

Chemineau P., Baril G., Leboeuf B., Maurel M.C., Roy F., Pellicer-Rubio M., Malpaux B. Cognie Y., 1999. Implications of recent advances in reproductive physiology for reproductive management of goats. J. Reprod. Fertil., 54, 129142.

Cognie Y., Poulin N., Pisselet C., Monniaux D., 1995. Effect of atresia on the ability of follicular fluid to support developmental competence of sheep oocytes in vitro. Theriogenology, 43(1), 188

Comizzoli P., Mermillod P., Cognie Y., Chai N., Legendre X., Mauge R., 2001. Successful in vitro production of embryos in the red deer (Cervus elaphus) and the sika deer (Cervus nippon). Theriogenology, 55, 649-659.

Curlewis J.D., Loudon A.S., Coleman A.P., 1988. Oestrous cycles and the breeding season of the Pere David's deer hind (Elaphurus davidia$n u s)$. J. Reprod. Fertil., 82, 119-126.

Dacheux J.L., Pisselet C., Blanc M.R., Hochereau-de Reviers M.T. Courot M. 1981. Seasonal variations in rete testis fluid secretion and sperm production in different breeds of ram. J. Reprod. Fertil., 61, 363-371.

Demmers K.J., Derecka K., Flint A., 2001. Trophoblast interferon and pregnancy. Reproduction, 121, 41-49.

Demmers K.J., Jabbour H.N., Deakin D.W., Flint A.P., 2000. Production of interferon by red deer (Cervus elaphus) conceptuses and the effects of roIFN-tau on the timing of luteolysis and the success of asynchronous embryo transfer. J. Reprod. Fertil., 118, 387-395.

Demmers K.J., Kaluz S., Deakin D.W., Jabbour H.N., Flint A.P., 1999. Production of interferon by the conceptus in red deer Cervus elaphus. J. Reprod. Fertil., 115, 59-65.

De Vos A., 1982. Deer farming: guidelines on practical aspects. FAO Animal Production and Health Paper, Rome, 27, 54p.

Dieleman S.J., Hendriksen P.J., Viuff D., Thomsen P.D., Hyttel P., Knijn H.M., Wrenzycki C., Kruip T.A., Niemann H., Gadella B.M., Bevers M.M., Vos P.L., 2002. Effects of in vivo prematuration and in vivo final maturation on developmental capacity and quality of pre-implantation embryos. Theriogenology, 57, 5-20. 
Dott H. M., Utsi M. N. P., 1971. The collection and examination of semen of the reindeer (Rangifer tarandus). J. Zool., 164, 419-424.

Fennessy P.F., Asher G.W., Bateson N.S., Dixon T.E., Hunter J.W., Bringans M.J., 1994. Embryo transfer in deer. Theriogenology, 41, 133-138.

Fennessy P.F., Fisher M.W., Shackell G.H., Mackintosh C. G., 1989. Superovulation and embryo recovery in Red deer (Cervus elaphus) hinds. Theriogenology, 32(5), 877-883.

Fennessy P.F., Mackintosh C.G., Shackell G.H., 1990. Artificial insemination of farmed red deer (Cervus elaphus). Anim. Prod., 51, 613621.

Fennessy P.F., Suttie J.M., 1985. Antler growth : nutritional and endocrine factors. P. F. Fennessy and K. R. Drew. Proceedings of international conference on the biology of deer production. The Royal Society of New Zealand Bull., 22, 239-250.

Flint A.P., Jabbour H.N., Loudon A.S., 1994. Oxytocin stimulates uterine prostaglandin F2 alpha secretion in red deer Cervus elaphus. Reprod. Fertil. Dev., 6, 269-271.

Flint A.P., Sheldrick E.L., McCann T.J., Brinklow B.R., Loudon A.S., 1991. Prostaglandin-induced secretion of oxytocin and prolactin in red (Cervus elaphus) and Pere David's (Elaphurus davidianus) deer hinds: evidence for oxytocin of luteal origin. Gen. Comp. Endocrinol. 83, 432-438.

Flint A.P., Albon S.D., Jafar S.I., 1997. Blastocyst development and conceptus sex selection in red deer Cervus elaphus: studies of a free-living population on the Isle of Rum. Gen. Comp. Endocrinol., 106, 374-383.

Flint A.P., Krzywinski A., Sempere A.J., Mauget R., Lacroix A., 1994. Luteal oxytocin and monoestry in the roe deer Capreolus capreolus. J. Reprod. Fertil., 101, 651-656.

Fukui Y., McGowan L.T., James R.W., Asher G.W., Tervit H. R., 1991. Effects of culture duration and time of gonadotropin addition on in vitro maturation and fertilization of red deer (Cervus elaphus) oocytes. Theriogenology, 35(3), 499-512.

Garcia A.J., Landete-Castillejos T., Garde J.J., Gallego L., 2002. Reproductive seasonality in female Iberian red deer (Cervus elaphus hispanicus). Theriogenology, 58, 1553-1562.

Garde J.J., Ortiz N., Garcia A.J., Gallego L., Landete-Castillejos T., Lopez A., 1998. Postmortem assessment of sperm characteristics of the red deer during the breeding season. Arch. Androl., 41, 195-202.

Gizejewski Z., 2004. Effect of season on characteristics of red deer (Cervus elaphus L.) semen collected using modified artificial vagina. Reprod. Biol., 4, 51-66.

Gizejewski Z., Snochowski M., Mayntz M., 2003. Fractions of the semen of red deer (Cervus elaphus) : their occurrence and characteristics in different periods of season. Pol. J. Vet. Sci., 6, 219-23.

Goeritz F., Quest M., Wagener A., Fassbender M., Broich A., Hildebrandt T. B., Hofmann R. R., Blottner S., 2003. Seasonal timing of sperm production in roe deer: interrelationship among changes in ejaculate parameters, morphology and function of testis and accessory glands. Theriogenology, 59(7), 1487-1502.

Gosch B., Fischer K., 1989. Seasonal changes of testis volume and sperm quality in adult fallow deer (Dama dama) and their relationship to the antler cycle. J. Reprod. Fertil., 85, 7-17.

Goss R.J., 1968. Inhibition of growth and shedding of antlers by sex hormones. Nature, 220, 83-85.

Goss R.J., 1969a. Photoperiodic control of antler cycles in deer. I Phase shift and frequency changes. J. Exp. Zool., 170, 311-324.

Goss R.J., 1969b. Photoperiodic control of antler cycles in deer. II Alteration in amplitude. J. Exp. Zool., 171, 223-234.

Green J.A., Xie S., Quan X., Bao B., Gan X., Mathialagan N., Beckers J.F., Roberts R.M., 2000. Pregnancy-associated bovine and ovine glycoproteins exhibit spatially and temporally distinct expression patterns during pregnancy. Biol. Reprod., 62, 1624-1631.

Guinness F., Lincoln G.A., Short R.V., 1971. The reproductive cycle of the female red deer Cervus elaphus L. J. Reprod. Fertil., 27, 427-438.

Guinness F.E., Albon S.D., Clutton-Brock T.H., 1978. Factors affecting reproduction in red deer (Cervus elaphus) hinds on Rhum. J. Reprod. Fertil., 54, 325-334.

Guler A., Poulin N., Mermillod P., Terqui M., Cognie Y., 2000. Effect of growth factors, EGF and IGF-I, and estradiol on in vitro maturation of sheep oocytes. Theriogenology, 54 209-218.

Guérin Y., Locatelli Y., Comizolli P., Mauget R., Mermillod P., Legendre X., Gatti J.-L., Dacheux J.L,. 2003. Conservation et utilisation du sperme épididymaire d'ovins et de cervidés en insémination artificielle et fécondation in vitro. Actes du B.R.G., 4, 173-183.

Haigh J.C., Cates W.F., Glover G.J., Rawlings N.C., 1984. Relationships between seasonal changes in serum testosterone concentrations, scrotal circumference and sperm morphology of male wapiti (Cervus elaphus). J. Reprod. Fertil., 70, 413-418

Hamasaki S., Yamauchi K., Ohki T., Murakami M., Takahara Y., Takeuchi Y., Mori Y., 2001. Comparison of various reproductive status in Sika deer (Cervus nippon) using fecal steroid analysis. J.Vet. Med. Sci., 63, 195-198.

Harder J.D., Woolf A., 1976. Changes in plasma levels of oestrone and oestradiol during pregnancy and parturition in white-tailed deer. J. Reprod. Fertil., 47, 161-163.

Harnal V. K., Spindler R., Monfort S. L., Pukazhenthi B., Bird D. M., Wildt D. E., 2001. Sperm capacitation in vitro in the eld's deer. Theriogenology, 56(3), 399-413.

Hishinuma M., Suzuki K., Sekine J., 2003. Recovery and cryopreservation of sika deer (Cervus nippon) spermatozoa from epididymides stored at 4 degrees $\mathrm{C}$. Theriogenology, 59(3-4), 813-820.

Hochereau-de Reviers M.T., Lincoln G.A. 1978. Seasonal variation in the histology of the testis of the red deer, Cervus elaphus. J. Reprod. Fertil., 54, 209-213.
Hosack D.A., Miller K.V., Ware L.H., Mashburn K.L., Morrow C.J., Williamson L.R. Marchinton R.L., Monfort S.L., 1999. Stag exposure advances the LH surge and behavioral estrus in Eld's deer hinds after CIDR device synchronization of estrus. Theriogenology, 51, 1333-1342.

Huang F., Cockrell D.C., Stephenson T.R., Noyes J.H., Sasser R.G., 1999. Isolation, purification, and characterization of pregnancy-specific protein B from elk and moose placenta. Biol. Reprod., 61, 1056-1061.

Jabbour H.N., Asher G.W., 1991. Artificial breeding of farmed fallow deer (Dama dama). In: Wildlife Production: Conservation and Sustainable Development, L.A. Renecker, R.J. Hudson (Eds), 485-491

Jabbour H.N., Asher G.W., Smith J.F., Morrow C.J., 1992. Effect of progesterone and oestradiol benzoate on oestrous behaviour and secretion of luteinizing hormone in ovariectomized fallow deer (Dama dama). J. Reprod. Fertil., 94, 353 361 .

Jabbour H.N., Marshall V.S., Argo C.M. Hooton J., Loudon A.S., 1994. Successful embryo transfer following artificial insemination of superovulated fallow deer (Dama dama). Reprod. Fertil. Dev., 6, 181-185.

Jabbour H.N., Veldhuizen F.A., Green G, Asher G.W., 1993. Endocrine responses and conception rates in fallow deer (Dama dama) following oestrous synchronization and cervical insemination with fresh or frozen-thawed spermatozoa. J. Reprod. Fertil., 98, 495-502.

Jabbour H.N., Veldhuizen F.A., Mulley, R.C., Asher G.W., 1994. Effect of exogenous gonadotrophins on oestrus, the LH surge and the timing and rate of ovulation in red deer (Cervus elaphus). J. Reprod. Fertil., 100, 533-539.

Jaczewski Z., Jasiorowski T., 1974 Observations on the electroejaculation in red deer. Acta Theriol., (Warsz) 19, 151-157.

Janovsky M., Tataruch F., Ambuehl M., Giacometti M., 2000. A Zoletil-Rompun mixture as an alternative to the use of opioids for immobilization of feral red deer. J. Wildl. Dis., 36, 663-669.

Kameyama Y., Miyamoto A., Kobayashi S., Kuwayama T., Ishijima Y., 2002. Annual changes in serum LH and testosterone concentrations in male Sika deer (Cervus Nippon). J. Reprod. Dev., 48, 613-617.

Karsch F.J., Legan S.J., Hauger R.L., Foster D.L., 1977. Negative feedback action of progesterone on tonic luteinizing hormone secretion in the ewe: dependence on the ovaries. Endocrinology, 101, 800-806.

Karsch F.J., Legan S.J., Ryan, K.D., Foster, D.L., 1980. Importance of estradiol and progesterone in regulating $\mathrm{LH}$ secretion and estrous behavior during the sheep estrous cycle. Biol. Reprod., 23, 404-413.

Kelly R. W., McNatty K. P., Moore G. H., 1985. Hormonal change around oestrus in female red deer. Proceedings of international conference on the biology of deer production. $P$. F. Fennessy, K. R. Drew. Royal Soc. New Zeal. Bull. 22, 181-184.

Kelly R.W., McNatty K.P., Moore G.H., Ross D., Gibb M., 1982. Plasma concentrations of LH, 
prolactin, oestradiol and progesterone in female red deer (Cervus elaphus) during pregnancy. J. Reprod. Fertil., 64, 475-483.

Khurana N.K., Niemann H., 2000. Effects of oocyte quality, oxygen tension, embryo density, cumulus cells and energy substrates on cleavage and morula/blastocyst formation of bovine embryos. Theriogenology, 54, 741-756

Krzywinski A., 1976. Collection of red deer semen with the artificial vagina. VIIIth International Congress on Animal Reproduction and Artificial Insemination, 1002-1005.

Krzywinski A., 1981. Freezing of post mortem collected semen from moose and red deer. Acta Theriol., 424-426.

Lambert R.T., Ashworth C.J., Beattie L., Gebbie F.E., Hutchinson J.S., Kyle D.J., Racey P.A., 2001. Temporal changes in reproductive hormones and conceptus-endometrial interactions during embryonic diapause and reactivation of the blastocyst in European roe deer (Capreolus capreolus). Reproduction, 121, 863871.

Lengwinat T., Meyer H.H., 1996. Investigations of $\mathrm{BrdU}$ incorporation in roe deer blastocysts in vitro. Anim. Reprod. Sci., 45, 103-107.

Li C; Littlejohn R.P., Corson I.D., Suttie J.M., 2003. Effects of testosterone on pedicle formation and its transformation to antler in castrated male, freemartin and normal female red deer (Cervus elaphus). Gen. Comp. Endocrinol., 131(1), 21-31.

Lincoln G.A., 1971. Puberty in a seasonally breeding male, the red deer stag (Cervus elaphus L.). J. Reprod. Fertil., 25, 41-54.

Lincoln G.A., 1998. Photoperiod-melatonin relay in deer. Acta Vet. Hung., 46, 341-356.

Lincoln G.A., Fraser H.M., Fletcher T.J., 1984. Induction of early rutting in male red deer (Cervus elaphus) by melatonin and its dependence on LHRH. J. Reprod. Fertil., 72, 339-343.

Lincoln G.A., Guinness F.E., 1972. Effect of altered photoperiod on delayed implantation and moulting in roe deer. J. Reprod. Fertil., 31, 455457.

Lincoln G.A., Kay, R.N., 1979. Effects of season on the secretion of LH and testosterone in intact and castrated red deer stags (Cervus elaphus). J. Reprod. Fertil., 55, 75-80.

Lincoln G.A., Tyler, N.J., 1999. Role of oestradiol in the regulation of the seasonal antler cycle in female reindeer, Rangifer tarandus. J. Reprod. Fertil., 115, 167-174.

Liu B.T., Cheng S.P., Huang M.C., Yu J.Y., 2002. Serum progesterone changes in luteal cyclicity and duration of estrous cycle in Formosan sika deer (Cervus nippon taiouanus) hinds. Zool. Sci., 19, 1033-1037.

Loudon A.S., Curlewis J.D., 1988. Cycles of antler and testicular growth in an aseasonal tropical deer (Axis axis). J. Reprod. Fertil., 83, 729738 .

Loudon A.S., Milne J.A., Curlewis J.D., McNeilly A.S., 1989. A comparison of the seasonal hormone changes and patterns of growth, voluntary food intake and reproduction in juvenile and adult red deer (Cervus elaphus) and Pere David's deer (Elaphurus davidianus) hinds. J. Endocrinol., 122, 733-745.

Luciano A.M., Modina S., Vassena R., Milanesi E., Lauria A., Gandolfi, F. 2004. Role of intracellular cyclic adenosine 3',5'-monophosphate concentration and oocyte-cumulus cells communications on the acquisition of the developmental competence during in vitro maturation of bovine oocyte. Biol. Reprod., 70, 465 472.

Malpaux B., Viguie C., Thierry J.C., Chemineau, P., 1996. Contôle photopériodique de la reproduction. Prod. Anim., 9, 9-23.

McCorkell R. B., MacDougall L., Adams G P., 2004. Ovarian follicle development in wapiti (Cervus elaphus) during the anovulatory season. Theriogenology, 61(2-3), 473-483.

McLeod B.J., Meikle L.M., Fisher M.W., Manley T.R., Heath D.A., McNatty, K.P., 2001a. Variation in antral follicle development during the follicular phase of the oestrous cycle in red deer (Cervus elaphus) hinds. Reproduction, 121, 697-705

McLeod B.J., Meikle L.M., Fisher M.W., Shackell G.H., Heath D.A., 2001b. Gonadotrophin-induced follicle development in red deer hinds during the breeding and nonbreeding seasons. Reproduction, 122, 111-119.

McMahon C.D., Fisher M.W., Mockett B.G., Littlejohn R.P., 1997. Embryo development and placentome formation during early pregnancy in red deer. Reprod. Fertil. Dev., 9, 723-730.

Meikle L.M., Fisher M.W., 1990. Induction oestrus in the ovariectomised red deer with exogenous progesterone and oestradiol benzoate. Proc. N. Z. Soc. Anim. Prod., 50, 155-160.

Meikle L.M., Fisher M.W., 1996. Regulation of reproductive seasonality in the red deer hind: oestradiol- dependent and -independent influences on the patterns of LH concentrations. J. Reprod. Fertil.,106, 213-220.

Moenter S.M., Woodfill C.J., Karsch F.J. 1991. Role of the thyroid gland in seasonal reproduction: thyroidectomy blocks seasonal suppression of reproductive neuroendocrine activity in ewes. Endocrinology, 128, 1337 1344.

Monfort S.L., Asher G.W., Wildt D.E., Wood T.C., Schiewe M.C., Williamson L.R., Bush M., Rall W.F., 1993a. Successful intrauterine insemination of Eld's deer (Cervus eldi thamin) with frozen-thawed spermatozoa. J. Reprod. Fertil., $99,459-465$

Monfort S.L., Brown J.L., Bush M., Wood T.C., Wemmer C., Vargas A., Williamson L.R., Montali R.J., Wildt D.E., 1993b. Circannual inter-relationships among reproductive hormones, gross morphometry, behaviour, ejaculate characteristics and testicular histology in Eld's deer stags (Cervus eldi thamin). J. Reprod. Fertil., 98, 471-480.

Monfort S.L., Wemmer C., Kepler T.H., Bush M., Brown J.L., Wildt D.E., 1990. Monitoring ovarian function and pregnancy in Eld's deer (Cervus eldi thamin) by evaluating urinary steroid metabolite excretion. J. Reprod. Fertil., $88,271-281$

Moore N.W., Robinson T.J., 1957. The vaginal response of the spayed ewe to repeated injections of oestradiol benzoate given alone or pre- ceded by progesterone. J. Endocrinol., 14, 297 303.

Mylrea G.E., Mulley R.C., English A.W., Evans G., 1999. Reproductive cycles of farmed female chital deer (Axis axis). Reprod. Fertil. Dev., 11, 167-173.

Park J.Y., Su Y.Q., Ariga M., Law E., Jin S.L., Conti M., 2004. EGF-like growth factors as mediators of $\mathrm{LH}$ action in the ovulatory follicle. Science, 303, 682-684

Peterson A. J., Ledgard A. M., Berg D. K., 1997. Conceptus development and associated fertility in red deer (Cervus elaphus) from days 11 to 25 after mating. Theriogenology, 47(1), 402. 97.

Plotka E D, Seal U S, Schmoller G C, Karns P D, Keenlyne, K D, 1977a. Reproductive steroids in the white-tailed deer (Odocoileus virginianus borealis). I. Seasonal changes in the female. Biol. Reprod. 16(3), 340-343. 77.

Plotka E.D., Seal U.S., Verme L.J., Ozoga J.J., 1977b. Reproductive steroids in the white-tailed deer (Odocoileus virginianus borealis). II. Progesterone and estrogen levels in peripheral plasma during pregnancy. Biol. Reprod., 17, 7883.

Plotka E.D., Seal U.S., Verme L.J., Ozoga J.J., 1980. Reproductive steroids in deer. III Luteinizing hormone, estradiol and progesterone around estrus. Biol. Reprod., 22, 576-581.

Plotka E.D., Seal U.S., Verme L.J., Ozoga J.J., 1982. Reproductive steroids in deer. IV. Origin of progesterone during pregnancy. Biol. Reprod., $26,258-262$.

Robinson T.J., 1954. Relationship of oestrogen and progesterone in oestrous behaviour of the ewe. Nature, 173,878 .

Robinson J. J., McDonald I., Fraser C., Crofts R. M. J., 1977. Studies on reproduction in prolific ewes. 1. Growth of the products of conception. J. Agric. Sci., 88, 539-552.

Roelants H., Schneider F., Goritz F., Streich J., Blottner S., 2002. Seasonal changes of spermatogonial proliferation in roe deer, demonstrated by flow cytometric analysis of c-kit receptor, in relation to follicle-stimulating hormone, luteinizing hormone, and testosterone. Biol. Reprod. $66,305-312$.

Rolf H.J., Fischer, K., 1996. Serum testosterone, 5-alpha-dihydrotestosterone and different sex characteristics in male fallow deer (Cervus dama): a long-term experiment with accelerated photoperiods. Comp. Biochem. Physiol. A Physiol., 115, 207-221.

Ropstad E., 2000. Reproduction in female reindeer. Anim. Reprod. Sci., 60-61, 561-570.

Ropstad E., Forsberg M., Sire J.E., Kindahl H., Nilsen T., Pedersen O., Edqvist L.E., 1995. Plasma concentrations of progesterone, oestradiol, LH and 15-ketodihydro-PGF2 alpha in Norwegian semi-domestic reindeer (Rangifer tarandus tarandus) during their first reproductive season. J. Reprod. Fertil., 105, 307-314.

Schon J., Goritz F., Streich J., Blottner S., 2004. Histological organization of roe deer testis throughout the seasonal cycle: variable and constant components of tubular and interstitial compartment. Anat. Embryol. (Berl) 208, 151-159. 
Sempere A., 1977. Plasma progesterone levels in the roe deer, Capreolus capreolus. J. Reprod. Fertil., 50, 365-366.

Sempere A. J., Blanvillain C., Mauget R., Lacroix A., Chemineau P., 1995. Effects of melatonin implantation or artificial long days on seasonal ovulatory activity in roe deer (Capreolus capreolus L.). Anim. Reprod. Sci., 38(1-2), 127136. 95.

Sempere A.J., Mauget R., Chemineau P., 1992. Experimental induction of luteal cyclicity in roe deer (Capreolus capreolus). J. Reprod. Fertil., 96, 379-384.

Shi Z.D., Barrell, G.K., 1994. Thyroid hormones are required for the expression of seasonal changes in red deer (Cervus elaphus) stags. Reprod. Fertil. Dev., 6, 187-192.

Sjaastad O.V., Blom A.K., Austad R., Oen E.O., 1990. Plasma progesterone in reindeer in relation to ovariectomy and hysterectomy. Acta Vet. Scand., 31, 45-51.

Snyder D.L., Cowan R.L., Hagen D.R., Schanbacher B.D., 1983. Effect of pinealectomy on seasonal changes in antler growth and concentrations of testosterone and prolactin in white-tailed deer. Biol. Reprod., 29, 63-71.

Soler A.J., Garcia A.J., Fernandez-Santos M.R., Esteso M.C., Garde J.J., 2003. Effects of thawing procedure on postthawed in vitro viability and in vivo fertility of red deer epididymal spermatozoa cryopreserved at -196 degrees C. J. Androl., 24, 746-756.

Spencer T.E., Bazer F.W., 2004. Conceptus signals for establishment and maintenance of pregnancy. Reprod. Biol. Endocrinol., 2, 49.

Suttie J.M., Fennessy P.F., Corson I.D., Laas F.J., Elgar H.J., Lapwood, K.R., 1989. LH and testosterone responses to GnRH in red deer (Cervus elaphus) stags kept in a manipulated photoperiod. J. Reprod. Fertil., 85, 213-219.
Suttie J.M., Fennessy P.F., Corson I.D., Veenvliet B.A., Littlejohn R.P., Lapwood K.R., 1992. Seasonal pattern of luteinizing hormone and testosterone pulsatile secretion in young adult red deer stags (Cervus elaphus) and its association with the antler cycle. J. Reprod. Fertil., 95, 925-933.

Suttie J.M., Fennessy P.F., Crosbie S.F., Corson, I.D., Laas F.J., Elgar H.J., Lapwood K.R. 1991. Temporal changes in LH and testosterone and their relationship with the first antler in red deer (Cervus elaphus) stags from 3 to 15 months of age. J. Endocrinol., 131, 467-474.

Suttie J.M., Lincoln G.A., Kay R.N., 1984. Endocrine control of antler growth in red deer stags. J. Reprod. Fertil., 71, 7-15.

Thompson J.G.E., Asher G.W., 1988. Superovulation and ova recovery in farmed fallow deer (Dama dama). Proc. Aust. Soc. Reprod. Biol., 20th. Ann. Conf., 4.

Vahtiala S., Sakkinen H., Dahl E., Eloranta E., Beckers J.F., Ropstad E., 2004. Ultrasonography in early pregnancy diagnosis and measurements of fetal size in reindeer (Rangifer tarandus tarandus). Theriogenology, 61, 785-795.

Webster J.R., Barrell G.K., 1985 Advancement of reproductive activity, seasonal reduction in prolactin secretion and seasonal pelage changes in pubertal red deer hinds (Cervus elaphus) subjected to artificially shortened daily photoperiod or daily melatonin treatments. J. Reprod. Fertil., 73, 255-260.

Webster J.R., Corson I.D., Littlejohn R.P., Stuart S.K., Suttie J.M., 1999. Effects of photoperiod on the cessation of growth during autumn in male red deer and growth hormone and insulin-like growth factor-I secretion. Gen. Comp. Endocrinol., 113, 464-477.

Willard S.T., Hughes Jr. D.M., Bringans M., Sasser R.G., White D.R., Jaques J.T., Godfrey R.W., Welsh Jr. T.H., Randel R.D., 1996.
Artificial insemination, hybridization and pregnancy detection in sika deer (Cervus nippon). Theriogenology, 46(5), 779-789.

Willard S.T., Petty S.J., Sasser R.G., White D.L., Randel R.D., 1999. Pregnancy detection and the effects of age, body weight, and previous reproductive performance on pregnancy status and weaning rates of farmed fallow deer (Dama dama). J. Anim. Sci., 77, 32-38.

Willard S.T., Randel R.D., 2002. Testicular morphology and sperm content relative to age, antler status and season in axis deer stags (Axis axis). Small Rum. Res., 45(1), 51-60.

Willard S.T., Sasser R.G., Jaques J.T., White D.R., Neuendorff D.A., Randel R.D., 1998. Early pregnancy detection and the hormonal characterization of embryonic-fetal mortality in fallow deer (Dama dama). Theriogenology, 49, 861-869.

Williams LM, Hannah L T, Kyle C.E., a Adam C.L., 1996. Central melatonin receptors in red deer (Cervus elaphus). Gen. Comp. Endocrin., 104(1), 1-6.

Wislocki G.B., Aub J.C., Waldo C.M., 1947. The effect of gonadectomy and administration of testosterone propionate on the growth of antlers in male and female deer. Endocrinology, 40, 202-224.

Xie S., Green J., Bixby J.B., Szafranska B., DeMartini J.C., Hecht S., Roberts R.M., 1997. The diversity and evolutionary relationships of the pregnancy-associated glycoproteins, an aspartic proteinase subfamily consisting of many trophoblast-expressed genes. Proc. Natl. Acad. Sci. USA, 94, 12809-12816.

Zomborszky Z., Zubor T., Toth J., Horn P., 1999. Sperm collection from shot red deer stags (Cervus elaphus) and the utilisation of sperm frozen and subsequently thawed. Acta Vet. Hung., 47, 263-270.

\section{Résumé}

Ces dernières années, l'élevage de cervidés s'est considérablement développé en Nouvelle-Zélande pour devenir une industrie profitable. Alors que quelques cervidés (daim d'Europe et cerf élaphe) font l'objet de domestication et d'élevage dans un but commercial, d'autres espèces et sous-espèces de cervidés sont menacées d'extinction dans le milieu naturel. Les travaux de recherches effectués afin de mieux caractériser et maîtriser la fonction de reproduction de ces ruminants sont présentés dans cette étude bibliographique.

Il apparaît qu'à l'instar de nos ruminants domestiques (ovins, caprins), les cervidés originaires des zones tempérées sont généralement caractérisés par un saisonnement marqué de leur fonction de reproduction. Ces variations saisonnières d'activité sexuelle sont dictées par les variations photopériodiques et permettent la naissance des jeunes en fin de printemps. Chez les cervidés, les différences entre les périodes d'activité et de repos sexuels semblent beaucoup plus marquées en comparaison de nos ruminants domestiques. La période d'activité sexuelle est variable d'une espèce à l'autre (été, automne ou début de l'hiver) mais très fixe pour une espèce donnée. La période de repos sexuel traduit des modifications importantes dans les sécrétions de gonadotrophines et se caractérise notamment par une aspermie complète chez le mâle. Chez la femelle, l'état d'anoestrus est profond et associé à une absence d'ovulation. La durée de gestation est également variable d'une espèce à l'autre mais est remarquablement fixe pour une espèce donnée.

Chez les cervidés originaires des zones subtropicales et selon les espèces, les variations d'activité sexuelle sont plus discrètes permettant une répartition des mises bas plus ou moins homogène au cours de l'année, y compris lorsque les animaux sont transportés sous des latitudes élevées.

Dans le cas des espèces de cervidés menacés d'extinction, l'utilisation des biotechnologies de la reproduction et des méthodes de procréation assistée pourrait, à terme, faciliter la réalisation des programmes conservatoires. Les techniques classiques de production in vivo d'embryons basées sur l'ovulation multiple, l'insémination artificielle et le transfert embryonnaire se sont avérées difficilement applicables aux cervidés. Aussi, les recherches portent actuellement sur le développement de techniques de production in vitro d'embryons. 


\begin{abstract}
Characteristics and control of reproduction in the Cervidae

In recent years, cervidae breeding has been considerably developed in New Zealand, now becoming a profitable industry. Even though some cervidae (fallow deer, red deer) are being domesticated and bred commercially, other species and sub-species of cervidae are threatened by extinction in their natural habitat. The research studies that have been performed in order to better characterise and control the reproduction function of these ruminants are presented in this bibliographic study.
\end{abstract}

It appears that as with our farm ruminants (ovines and caprines), the cervidae coming from temperate zones are generally characterised by the marked seasonality of their reproduction function. These seasonal variations of sexual activity are led by photoperiodic variations and allow the birth of the young at the end of the spring. With the cervidae, the differences between the periods of sexual activity and rest are much more marked in comparison with farm animals. The period of sexual activity is variable from one species to another (summer, autumn, or at the beginning of the winter) but is set for each species. The period of sexual rest translates important modifications in the gonadotrophin secretions and can notably be characterised by total aspermia in males. In the female, the state of anoestrus is deep and associated with an absence of ovulation. The length of gestation is also variable from one species to another but is set for each species.

In the cervidae originating from subtropical zones and depending on the species, the variations in sexual activity are discreet, allowing a more or less homogenous distribution of births over the year, including when the animals are led to higher latitudes.

For the cervidae species threatened by extinction, the use of reproduction biotechnology and assisted-procreation methods could on the long term help conservation programmes. The classical techniques of in vivo production of embryos based on multiple ovulation, artificial insemination and embryo transfer have been found to be difficult in the cervidae. In addition, current research is focussed on the development of techniques of in vitro production of embryos.

LOCATELLI Y., MERMILLOD P. 2005. Caractéristiques et maîtrise de la fonction de reproduction chez les cervidés. INRA Prod. Anim. 18, 3-25. 
